US Army Corps

of Engineers $s_{\circledast}$

Engineer Research and

Development Center

Simulation Tools for Combat Vehicle Robotics

\title{
An Investigation of the Feasibility of Assimilating CosMos Soil Moisture into GeoWATCH
}

John B. Eylander, Michael G. Lewis, Maria T. Stevens, John G. Green, September 2021 Stephanie J. Price, and Joshua R. Fairley 
The US Army Engineer Research and Development Center (ERDC) solves the nation's toughest engineering and environmental challenges. ERDC develops innovative solutions in civil and military engineering, geospatial sciences, water resources, and environmental sciences for the Army, the Department of Defense, civilian agencies, and our nation's public good. Find out more at www.erdc.usace.army.mil.

To search for other technical reports published by ERDC, visit the ERDC online library at https://erdclibrary.on.worldcat.org/discovery. 
ERDC TR-21-15

September 2021

\title{
An Investigation of the Feasibility of Assimilating CosMos Soil Moisture into GeoWATCH
}

\author{
John B. Eylander \\ Coastal and Hydraulics Laboratory \\ US Army Engineer Research and Development Center \\ 3909 Halls Ferry Rd \\ Vicksburg, MS 39180-6199 \\ Michael G. Lewis \\ Geospatial Research Laboratory \\ US Army Engineer Research and Development Center \\ 7701 Telegraph $R d$ \\ Alexandria, VA 22315-3822 \\ Maria T. Stevens, John G. Green, Stephanie J. Price, and Joshua R. Fairley \\ Geotechnical and Structures Laboratory \\ US Army Engineer Research and Development Center \\ 3909 Halls Ferry Rd \\ Vicksburg, MS 39180-6199
}

Final report

Approved for public release; distribution is unlimited.

Prepared for Deputy Assistant Secretary of the Army (Research and Technology) 102 Army Pentagon

Washington, DC 20314-1000

Under Program Element No. 0633462A; Project No. 480361; Task No. SBG302 


\section{Abstract}

This project objective evaluated the potential of improving linked weatherand-mobility model predictions by blending soil moisture observations from a Cosmic-ray Soil Moisture Observing System (COSMOS) sensor with weather-informed predictions of soil moisture and soil strength from the Geospatial Weather-Affected Terrain Conditions and Hazards (GeoWATCH). Assimilating vehicle-borne COSMOS observations that measure local effects model predictions of soil moisture offered potential to produce more accurate soil strength and vehicle mobility forecast was the hypothesis. This project compared soil moisture observations from a COSMOS mobile sensor driven around an area near Iowa Falls, IA, with both GeoWATCH soil moisture predictions and in situ probe observations. The evaluation of the COSMOS rover data finds that the soil moisture measurements contain a low measurement bias while the GeoWATCH estimates more closely matched the in situ data. The COSMOS rover captured a larger dynamic range of soil moisture conditions as compared to GeoWATCH, capturing both very wet and very dry soil conditions, which may better flag areas of high risk for mobility considerations. Overall, more study of the COSMOS rover is needed to better understand sensor performance in a variety of soil conditions to determine the feasibility of assimilating the COSMOS rover estimates into GeoWATCH.

DISCLAIMER: The contents of this report are not to be used for advertising, publication, or promotional purposes. Citation of trade names does not constitute an official endorsement or approval of the use of such commercial products. All product names and trademarks cited are the property of their respective owners. The findings of this report are not to be construed as an official Department of the Army position unless so designated by other authorized documents. 


\section{Contents}

Abstract........................................................................................................................... if

Figures and Tables.................................................................................................... iv

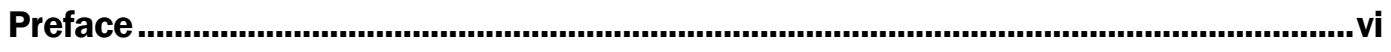

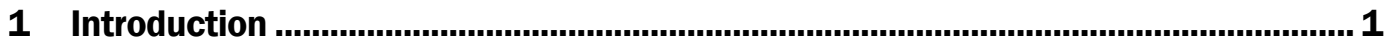

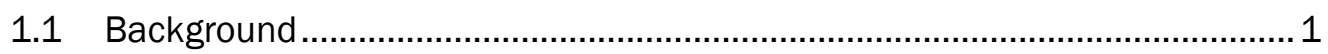

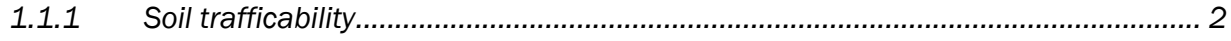

1.1.2 Soil texture ..................................................................................................... 4

1.1.3 GeoWATCH application description ................................................................. 4

1.1.4 Soil moisture remote sensing............................................................................... 6

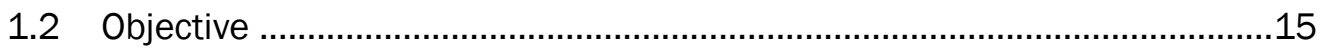

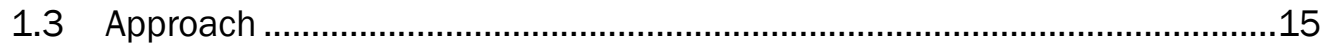

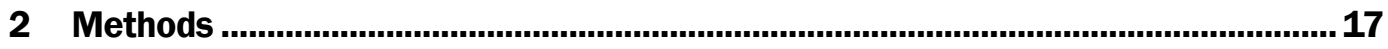

2.1 Integration of locally sensed data with exogenous spatial data...................17

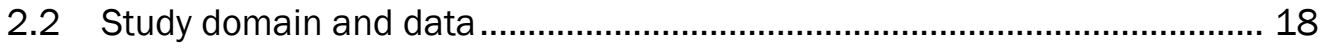

2.3 Cosmic-ray Soil Moisture Observing System (COSMOS) rover

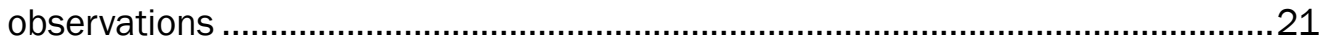

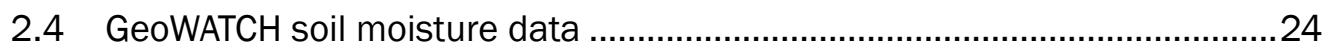

2.5 COSMOS-GeoWATCH spatial matching methods ....................................... 25

2.6 COSMOS rover observation filtering ........................................................27

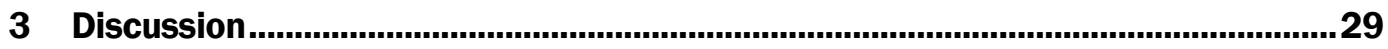

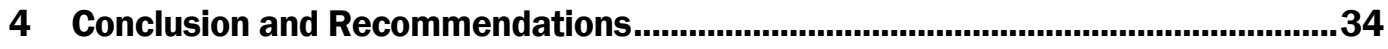

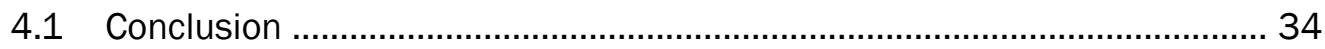

4.2 Recommendations for future research ................................................ 34

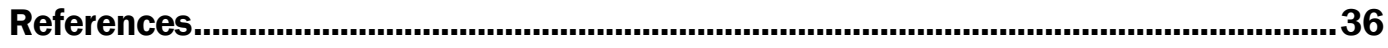

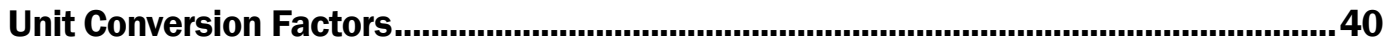

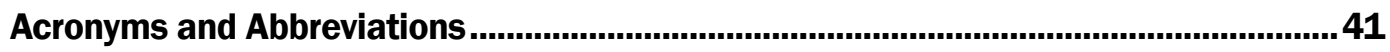

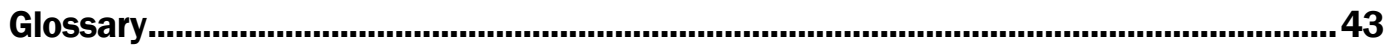

Report Documentation Page 


\section{Figures and Tables}

\section{Figures}

Figure 1. A soldier with a cone penetrometer (left) and a complete trafficability kit (right) with cone penetrometer and remold tools.

Figure 2. Vertical cutoff rigidity for 1980 from (Desilets et al. 2006). Vertical cutoff rigidity and attenuation length are linked and therefore exhibit the same field characteristic.

Figure 3. Google Earth image with road network overlay image of the study domain surrounding lowa Falls, IA. The black dots with labels are locations of in situ soil moisture probes placed as part of the SMAPVEX16 project.

Figure 4. Map of the study domain with colored circles representing the COSMOS observation. A distance scale bar is located in the upper left of the image for reference. The red colors represent omitted observations. The brown-to-green circles are valid observations representing dry-to-wet estimates from COSMOS. A reference color bar is in the lower right corner.

Figure 5. Study domain maps of USGS Land Use Classification map (left) and USDA Soil Texture classification map (right). The land use is primarily categorized as cultivated according to the NLCD 2016 data (blue colors) with some urban (red), forest (green colored areas) and water. The soils are primarily loams (white color) with some silty clay loam (blue) and silty (brown) soils.

Figure 6. Raw neutron counts from the (a) N1 and (b) N2 sensors in the ERDC COSMOS rover along with the temperature (c) and resulting computed soil moisture (d).

Figure 7. Histogram of the ERDC COSMOS rover volumetric soil moisture estimates (left) and the map of the rover observation (right) with colors representing the computed volumetric soil moisture estimate.

Figure 8. GeoWATCH volumetric soil moisture analysis valid 29 May 2016 at 18 UTC with overlayed an Openstreet map. Included are the ERDC COSMOS rover observation locations (colored circles) and the locations of in situ soil moisture observations (black circles). Red circles represent COSMOS observations that were omitted from comparison due to the proximity of water near the observation or because the observation was taken primarily in area classified as urban or dense urban by the NCLD 2016.

Figure 9. a) Graph of weighting function with distance; b) the resulting $16 \times 16$ array of relative weights computed for the GeoWATCH data.

Figure 10. Volumetric soil moisture estimates from the COSMOS rover (blue crosses) and the GeoWATCH weighted average (orange dots) vs. time.

Figure 11. Scatter plot of COSMOS rover soil moisture estimates plotted against weighted GeoWATCH soil moisture analyses. The rover observation time is considered in the GeoWATCH weighted averaging, making the weighted average a compilation of GeoWATCH analysis times from 15 UTC 29-May-2016 to 00 UTC on 30 May 2016.

Figure 12. Histogram of GeoWATCH data for COSMOS locations (left) and the entire 00 UTC 30-May-2016 GeoWATCH dataset (right). 
Figure 13. Plots of in situ soil moisture observations for SMAPVEX16 sites 733 (left) and 743 (right) with soil moisture estimates from the weighted average GeoWATCH-matched estimates (red circles) and the COSMOS values (green triangles).

Figure 14. Plot of the in situ soil moisture probes for the 17 different SMAPVEX16 sites compare to the GeoWATCH soil moisture estimates. The root mean square error is listed in the upper right of the plot. Each SMAPVEX16 site is labeled with a different symbol shape and color combination. There were four time periods evaluated, matching the observation time of the GeoWATCH data $(15,18,21$, and 00 UTC).

Figure 15. Comparison of the first $15 \mathrm{~min}$ (left) and last $15 \mathrm{~min}$ (right) of COSMOS rover observations (green line) with GeoWATCH area weighted soil moisture estimates (red dashed line). During the first and last 15 min of rover operations, the vehicle was stationary, so the observations represent a single location. The average value of the COSMOS rover estimates is the brown line.

\section{Tables}

Table 1. Hydrogen pools interacting with COSMOS signal (adapted from Adreasean et al. 2017). 


\section{Preface}

This study was conducted for the Deputy Assistant Secretary of the Army (Research and Technology) under Program Element No. 0633462A; Project No. 480361; Task No. SBG302.

The work was performed by the Hydrologic Systems Branch of the Coastal, Flood and Storm Protection Division, Coastal and Hydraulics Laboratory (CHL); the Data Signature and Analysis Branch of the Topography, Imagery, and Geospatial Research Division, Geospatial Research Laboratory; and the Mobility Systems Branch of the Engineering Systems and Materials Division, Geotechnical and Structures Laboratory of the US Army Engineer Research and Development Center (ERDC).

At the time of publication of this report, Dr. Hwai-Ping Cheng was Chief, Hydrologic System Branch; Mr. Adam Burnstein was Acting Chief, Data Signature and Analysis Branch; Dr. P. Jeff Durst was Chief, Mobility Systems Branch; Dr. Cary A. Talbot was Chief, Flood and Storm Protection Division; Ms. Jennifer Smith was Chief, Topography, Imagery, and Geospatial Research Division; Mr. Justin Strickler was Chief, Engineering Systems and Materials Division; and Mr. Nicholas Boone was the Technical Director for Military Engineering, Force Projection. The Deputy Director of ERDC-CHL was Mr. Keith Flowers, and Dr. Ty V. Wamsley was the Director. The Deputy Director of ERDC-GRL was Ms. Valerie Carney, and the Director was Mr. Gary Blohm. The Deputy Director of ERDC-GSL was Mr. Charles Ertle, and the Director was Mr. Bartley Durst.

COL Teresa A. Schlosser was the Commander of ERDC, and the Director was Dr. David W. Pittman. 


\section{Introduction}

As the US Army prepares for future conflicts, the Next Generation Combat Vehicle Cross-Functional Team has the responsibility to oversee acquisition of several new combat vehicles, including unmanned vehicles. Not only will these vehicles be required to traverse the same types of challenging terrain that the Army has always faced, but they will also have additional challenges of correctly interpreting their environments without a human driver in the loop. To this end, the US Army Engineer Research and Development Center (ERDC) is building upon its legacy in ground vehicle mobility to develop new tools for an adaptive learning mobility model that a vehicle could use to learn more about its environment as it drives.

\subsection{Background}

This technical report documents the comparison of remotely sensed soil moisture estimates from the Cosmic-ray Soil Moisture Observing System (COSMOS) (Desilets et al. 2010) to both in situ soil moisture measurements and Geospatial Weather-Affected Terrain Conditions and Hazards (GeoWATCH) (Ueckermann et al. 2018) gridded soil moisture products focused on a specific study domain around Iowa Falls, IA. The COSMOS measurements were previously gathered as part of an ERDC contribution to the Soil Moisture Active/Passive (SMAP) Validation Experiment 2016 (SMAPVEX16) (Chan et al. 2018). This feasibility study focuses on a single day of COSMOS rover observations, May 29, 2016, starting at approximately o9oo local time (1400 UTC) and extending into the evening (oooo UTC). In addition to incorporating real-time weather analyses and forecasts from the $557 \mathrm{WW}$, the GeoWATCH system contains an archive of National Aeronautics and Space Administration (NASA) Land Information System (LIS) (Kumar et al. 2008) land data assimilation system output data from the USAF 557th Weather Wing operational version of LIS that can be used to downscale and generate historical assessments of soil moisture, soil strength, and vehicle speeds with products available in $3 \mathrm{hr}^{1}$ temporal increments (00, 03, 06, 09, 12, 15, 18, and 21 UTC), enabling this retrospective comparison. The in situ observations were obtained from

\footnotetext{
1 For a full list of the spelled-out forms of the units of measure used in this document, please refer to US Government Publishing Office Style Manual, 31st ed. (Washington, DC: US Government Publishing Office 2016), 248-52, https://www.govinfo.gov/content/pkg/GPO-STYLEMANUAL-2016/pdf/GPOSTYLEMANUAL-2016.pdf.
} 
partners ${ }^{1}$ on the SMAPVEX16 project for a number of sites around the study domain. Finally, the GeoWATCH and COSMOS observations needed to be matched spatially to more directly compare their assessments since the COSMOS observations area generally representing a wider area than the $30 \mathrm{~m}$ soil moisture model-based estimates. This technical report provides an overview of the domain, geospatial data used to support the analysis, the methods used to rescale the GeoWATCH observations to match the COSMOS area representation, the evaluation of the comparisons and assessment of the feasibility of assimilating the COSMOS data into GeoWATCH.

\subsubsection{Soil trafficability}

Ground vehicle off-road mobility in soft soil has long been recognized as a significant factor in military mission planning and execution (WES 1961; US Army 1959; US Army 1990; US Army 2010). Low soil strength is among the top causes of terrain inaccessibility. Moreover, soil strength is a terrain variable that is not necessarily obvious from visual inspections either by human drivers or by the lidar- and camera-based perception systems commonly used onboard autonomous vehicles.

Historically, trafficability kits have been deployed for operational use so that soldiers can scout soil strength along anticipated travel routes (US Army 1959) (Figure 1). These kits were designed to use a robust, simple hand-held trafficability cone penetrometer to measure cone index (CI), which is an index of the soil shear strength. A remolding set was also included to allow improved estimates that accounted for the propensity of some fine-grained soils to lose strength with traffic, a property quantified by the remold index (RI). The product of CI and RI results in a modified strength estimate, the rating cone index (RCI). RCI can be directly compared to a vehicle configuration's minimum required soil strength, known as the vehicle cone index (VCI) (Stevens et al. 2013). In this way, simple field measurement devices can give soldiers a rapid answer to the relative trafficability of a certain area for a particular vehicle.

\footnotetext{
1 Michael Cosh. Personal communication.
} 
Figure 1. A soldier with a cone penetrometer (left) and a complete trafficability kit (right) with cone penetrometer and remold tools.

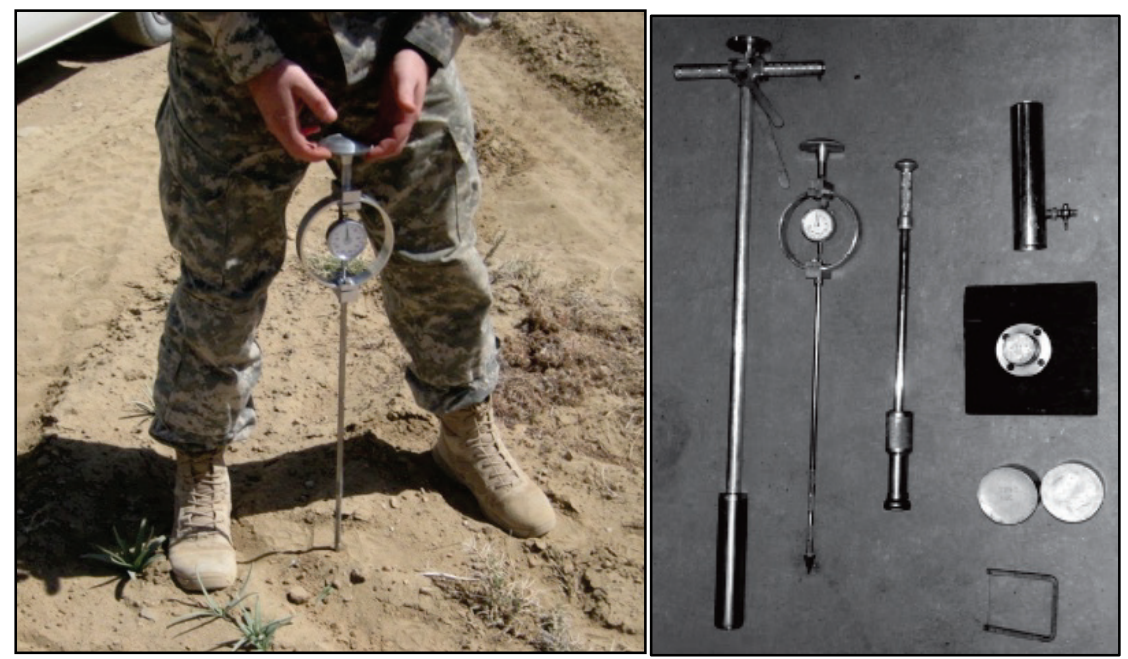

However, for mobility simulations and operations planning, it is often not possible to measure in situ RCI. Thus, RCI must be estimated remotely based on knowledge of soil and environment characteristics. Several US Army Corps of Engineers (USACE) models have used soil and meteorological parameters to estimate RCI. Some of these models are soil moisture strength prediction (SMSP) (Sullivan et al. 1997); Short-term Operational Forecasts of Trafficability (Mason et al. 2001); and Fast All Season Soil Strength (FASST) (Frankenstein and Koenig 2004). Generally, these models involve first using meteorological data to estimate soil moisture and then estimating RCI from soil moisture using empirical relationships. The relationships also require knowledge of the Unified Soil Classification System (USCS) (ASTM International 2006) soil type for the region of interest.

Cross-country mobility (CCM), in the form of vehicle speed maps, is often estimated numerically using the NATO Reference Mobility Model (NRMM) (Ahlvin and Haley 1992) or its derivatives, Mobility Analysis Tool (MAT) and Standard Mobility Application (StndMob). MAT (Priddy et al. 2019) is a new US-only mobility model based on NRMM 2.8.2. StndMob (Baylot et al. 2005) is a Python-based application used to apply NRMM pre-computed vehicle references and terrain information produce CCM results. For the purpose of this study, the most important feature of these mobility models is that they can each use RCI inputs to influence terrain-limited vehicle speed off road. 


\subsubsection{Soil texture}

Soil texture is the principal attribute of a soil that determines how it will respond to moisture. It is the measure of grain size distribution within soil and consequently provides hints toward the soil porosity. Soil textural classes, using the US Department of Agriculture (USDA) taxonomy, are generally defined by the proportion of the soil that falls into three categories: sand (>0.05 mm), silt (0.05-0.002 mm), and clay (<0.002 $\mathrm{mm})$. Lower requirement analysis differentiating only course grained soils from fine grain soils generally use the $0.075 \mathrm{~mm}$ threshold for over $50 \%$ of the grains as the boundary.

Currently, land surface models use world maps of soil texture to inform water balances. Improvements to these maps, via remote or proximal sensors (e.g., Lacerda et al. 2016) would also improve soil strength estimates.

Note that the USDA texture taxonomy used for moisture analysis cannot be directly translated to the Unified Soil Classification System (USCS) soil classifications used in trafficability analysis, although several approximations have been made (Garcia-Gaines and Frankenstein 2015).

\subsubsection{GeoWATCH application description}

The GeoWATCH application was developed to help bridge the gap between weather-scale products and Army-scale product needs that support cross-country mobility and other similar applications. The soil moisture downscaling algorithms, geospatial display, and web application were developed by Creare, LLC, with USACE support through the Army Small Business Innovative Research and Army Rapid Innovation Fund programs. The GeoWATCH system was designed to provide the Army a capability to produce higher-resolution soil moisture analyses supporting Army needs than the products supplied by the US Air Force (USAF) $557^{\text {th }}$ Weather Wing (557WW), the authoritative supplier of weather data to the Army. The GeoWATCH algorithms ingest soil moisture analyses and predictions from the USAF 557WW produced by the Land Information System (Peters-Lidard et al. 2007; Kumar et al. 2008a) and Global Air Land Weather Exploitation Model (GALWEM) (Stoffler 2017) using published web coverage services (WCS) to support a machine-to-machine functionality. The WCS retrievals pull 26 weather forcing products from both the 557WW operational LIS analyses and GALWEM forecasts, the 
number and type of parameters required to run a land surface model at higher resolution than executed by the USAF. The USAF weather modeling systems are executed every $6 \mathrm{hr}, 365$ days a year, at spatial resolutions of $25 \mathrm{~km}$ and $10 \mathrm{~km}$, respectively, and produce two gridded analyses valid every $3 \mathrm{hr}$, and forecasts out to 10 days. The GeoWATCH system retrieves those forecasts as soon as they are available, enables the on-demand downscaling for both the analysis and forecast fields, and supports a mobility prediction out to $144 \mathrm{hr}$ (6 days).

The GeoWATCH downscaling algorithms are supported by combining the LIS and GALWEM-based soil moisture analyses and forecasts with global fine-resolution terrain condition information, including terrain elevation and slope, soil texture, and vegetation condition assessments, to create a finer-resolution surface soil moisture estimate matching the resolution of the terrain data (Bieszczad et al. 2016). The GeoWATCH product resolutions match the fine resolution of the input terrain data $(30-90 \mathrm{~m}$ spatially), driven by a topographic wetness index-based algorithm developed by Creare, LLC. The terrain data include elevation and slope from Digital Terrain Elevation Data and other higher-resolution spatial elevation products provided by partner defense agencies, soil texture information from the USDA within the United States, and land use and vegetation data from the US Geological Survey. Global sources of soil texture and vegetation datasets were provided by the National GeospatialIntelligence Agency via the SoilScape and Visual Navigation products.

The restricted version of the GeoWATCH web application links the downscaling algorithm results to Army soil strength algorithms using a USDA-to-Unified Soil Classification System soil texture cross-reference map (Garcia-Gaines and Frankenstein 2015) and also supports military users to directly generate cross-country mobility speed estimates through a drop-down menu selection that initiates a python version of the US Army Standard Mobility Application (StndMob) (Baylot et al. 2005).

The GeoWATCH products are currently available through a real-time web site maintained by Creare, LLC, on the Amazon GovCloud web servers as well as on the USACE Model Interface Platform for US Government users with proper credentials (common access card). All GeoWATCH data are available to be downloaded in GeoTIFF format using a web service retrieval application interface for privileged users. The GeoTIFF-formatted 
data can be read in and interrogated to any GIS application, or simply viewed by an image viewer.

\subsubsection{Soil moisture remote sensing}

\subsubsection{Soil moisture from microwave}

Remote sensing of soil moisture is most sensitive in the electromagnetic spectrum in the range of 1 to $5 \mathrm{GHz}$ due to the maximum stretching of the dielectric effect of dry soil to water. In the range of $1.4-1.427 \mathrm{GHz}$, the L-band, not only is the signal most sensitive to soil moisture but the atmosphere is nearly transparent, and vegetation is semi-transparent allowing nearly universal viewing at the soil surface (Monerris and Schmugge 2009). The challenge to using such frequencies is the requirement for a large antenna for even very low resolution; using classical orbiting arrangement without any novel approach, a $50 \mathrm{~km}$ resolution would require a $20 \mathrm{~m}$ antenna (Monerris and Schmugge 2009). Further confounding interpretation of microwave-based remote sensing is the response to variations of surface roughness. The response is not constant but variable based on moisture content and soil type (Panciera et al. 2009), with clay soils demonstrating noticeably more aberrant response from other types (Monerris and Schmugge 2009).

This has been the primary area of investigation into soil moisture remote sensing in recent years primarily due to the soil moisture sensitivity, but due to the size of the wavelength, the resolution will remain rather coarse. The European Space Agency Soil Moisture and Ocean Salinity (SMOS) radio telescope containing the Microwave Imaging Radiometer using Aperture Synthesis sensor was the first mission where soil moisture remote sensing was a primary objective. The SMOS satellite was launched in 2009, with a return period of 3 days and a pixel size of $40 \mathrm{~km}$ (Merlin et al. 2008). The NASA Soil Moisture Active Passive (SMAP), mission launched in 2015 attempted to produce a higher-resolution product with a resolution better than $10 \mathrm{~km}$ using a combination of both a highly accurate and low resolution passive radiometer with higher resolution active microwave, which is prone to vegetation and surface roughness effects (Wu et al. 2015). Unfortunately, SMAP suffered an irrecoverable system failure in the active microwave portion of the sensor, leading to the passive radiometer being the only usable sensor upon the instrument. 
Land data assimilation systems, including the LIS system, were developed to combine the remotely sensed land measurements, including soil moisture, with other weather and terrain information to compute soil moisture, temperature, and surface energy budget analyses globally for use in weather and climate prediction models. NASA successfully demonstrated assimilating multiple remotely sensed soil moisture datasets (Kumar et al. 2014, 2008b; Reichle et al. 2002) from multiple microwave satellite sensors. The 557WW operational version of LIS operationally incorporates both SMAP and European Organisation for the Exploitation of Meteorological Satellites Advanced Scatterometer sensor data using an ensemble Kalman filter data assimilation algorithm. The combination of model and remote sensing increases the accuracy of the LIS soil moisture estimates, enables global analyses to be constantly computed at hourly temporal availability, and provides a more accurate initialization of the weather forecast models as well as any other downstream applications (e.g., GeoWATCH downscaling algorithms).

\subsubsection{Soil moisture from neutron detection}

Neutron moderation, another method of estimating soil moisture content, is based on emission of fast neutrons from a decaying radioactive source. When the fast neutrons collide with a proton $\mathrm{H}^{+}$, they slow down. Since the primary source of hydrogen in most soils is water, the proportion of slowed neutrons is directly proportional to the soil moisture content. This moderation is due to the elastic nature of the scattering from neutronhydrogen interaction, where the lower an atomic number, the more elastic the interaction. The elasticity refers the transference of energy between particles, whereas an inelastic scattering interaction indicates transference of energy within a particle. It is not that neutrons are particularly choosy about which atoms they interact with, but in atoms with larger atomic numbers, the interaction becomes more inelastic and the neutrons are not likely to return to the detector.

This method, although highly accurate, requires the use of radioactive materials, making it a safety hazard. Furthermore, readings are not instantaneous as the readings require a buildup of slowed neutrons to detect the amount of moisture present in the sphere of interaction. Calibration must account for organic matter, as these are high in hydrogen, as well as soil type as the sphere of influence will reduce in finer soils, which can hold more water than courser soils. Additionally, the sphere of influence is variable depending on soil moisture as more water 
creates a larger impedance to hydrogen while drier soils create less of an impedance, so the fast neutrons travel further. This final point imbues an uncertainty into the reading as the sphere of influence is variable (MunozCarpena 2004).

The drawback to traditional neutron detection methods is the use of an active source, Americium 241/Beryllium. The active source material transmits high energy fast neutrons that collide with hydrogen and lose their energy, becoming slow neutrons. Some slow neutrons are transmitted back to the detector, which counts the total number of hits providing an estimate of hydrogen density. The use of this active source requires training, licensing, and inspection, due to the radioactive nature of the active source material.

\section{COSMOS (Cosmic-ray Soil Moisture Observing System)}

In the search for increased resolution of large-scale soil moisture mapping for climate and hydrological forecasting, Zreda et al. (2008) proposed using a neutron detector that utilized the ambient background neutrons as opposed to the more traditional active neutron detectors used previously. Fast neutrons are generated by collisions of primary cosmic rays with atmospheric nuclei creating a cascade of secondary neutrons (Zreda et al. 2008). These fast neutrons are moderated by hydrogen atoms present in the soil, the vast majority of which are associated with water. A strong inverse correlation exists between the hydrogen content of a soil and the intensity of low-energy neutrons (Zreda et al. 2008). The precision of such a method is calculated to approximately $1.9 \%$ over $1 \mathrm{hr}$ although this is highly dependent on moisture content as the total time required to achieve a sufficient number of counts is moderated by the hydrogen content and can range from $0.1 \mathrm{hr}$ to $4 \mathrm{hr}$ for soils with a moisture content from $5 \%$ to 30\% (Zreda et al. 2008).

The use of cosmic-ray neutrons in measuring average area soil moisture is a newer method in remote measurement although the use of neutrons for soil moisture monitoring is over half a decade old. Measurements can be made in both a stationary time series and through mobile instantaneous snapshots (Ochsner et al. 2013). Ambient neutron fluxes are a proxy for soil moisture in both liquid and solid forms (Desilets et al. 2010). The source of the neutrons that are measured originates in a cascading process that occurs from cosmic-ray protons exciting nuclei in the upper 
atmosphere. Hydrogen from water, and to a much lesser degree carbon, has a moderating effect on those fast neutrons. Fast neutrons are those not in thermal equilibrium with the surrounding medium, in this case excited by the cosmic-ray proton. Changes to the water content in soil directly changes the amount of moderating hydrogen available to interact with fast neutrons, that in turn shifts the equilibrium concentration of neutrons at the surface (Ochsner et al. 2013).

While this method has been used successfully, there are some inherent problems arising from the nature of the detection. The sensing area of a detector is somewhat variable as additional moisture decreases the effective radius of the measured hydrogen as the neutrons encounter a denser hydrogen field and thus higher resistance. This is true of both air and soils and can modify the measurement by providing a variable resolution. This occurs in both the horizontal and vertical direction with a penetration of up to $70 \mathrm{~cm}$ in dry soil to approximately $12 \mathrm{~cm}$ in saturated soils (Ochsner et al. 2013) and a horizontal influence of approximately $600 \mathrm{~m}$ diameter in dry air. While the base footprint is approximately a $300 \mathrm{~m}$ radius, atmospheric water reduces the footprint by approximately $20 \mathrm{~m}$ for every $0.01 \mathrm{~kg} / \mathrm{kg}$ increase in specific humidity, while soil moisture affects the radius to a much smaller degree (Andreasen et al. 2017). Neutrons interact with all forms of hydrogen near the surface, so accurate measurement of soil moisture cannot be obtained without a consistent measured value for other interacting hydrogen reservoirs, which include surface water, lattice water, vegetation (addressed later), and atmospheric water (Table 1) (Ochsner et al. 2013).

Furthermore, calibration errors, sometimes significant, are known to arise in soils with high clay content (Grismer et al. 1995). However, the accuracy should be adequate, over the considerable number of data points that will be used, to prove useful, and as the footprint of the sensor is most similar to remote sensing options, it tends to show high agreement with remote sensing results. 
Table 1. Hydrogen pools interacting with COSMOS signal (adapted from Adreasean et al. 2017).

\begin{tabular}{|l|c|c|c|}
\hline Medium & Static & Quasi-static & Dynamic \\
\hline Soil Moisture & & & $\mathrm{X}$ \\
\hline Biomass & & $\mathrm{X}$ & \\
\hline Soil organic carbon & & $\mathrm{X}$ & \\
\hline Lattice water & $\mathrm{X}$ & & \\
\hline Snow & & & $\mathrm{X}$ \\
\hline Open water & & $\mathrm{X}$ & \\
\hline Canopy intercepted water & & & $\mathrm{X}$ \\
\hline Built environment & $\mathrm{X}$ & & \\
\hline Atmospheric water vapor & & & $\mathrm{X}$ \\
\hline
\end{tabular}

However, even with these known issues, field level soil moisture measured by the rover was found to have a root mean squared difference of 0.03 $\mathrm{cm}^{3} / \mathrm{cm}^{3}$ over averaged in situ impedance probes in (Dong et al. 2014) and the regional $\mathrm{o} \mathrm{cm}$ to $5 \mathrm{~cm}$ depth soil moisture was found to be within \pm $.03 \mathrm{~cm}^{3} / \mathrm{cm}^{3}$ of the best available independent estimates. This represents a method that is largely local with minimal processing needs to provide highly accurate critical layer soil moisture on the fly.

\section{COSMOS calculations, from neutron counts to soil moisture}

The fundamental basis of the COSMOS sensor is that neutrons form an exogeneous relatively consistent background on the earth of which the density can be described to a somewhat precise level. These neutrons interact with hydrogen in a primarily uniform way which can be measured. Therefore, describing the way an instrument responds to these neutronhydrogen interactions can provide a relatively consistent measure of hydrogen within the sensor's footprint, which is approximately a $600 \mathrm{~m}$ radius surrounding the sensor (Desilets et al. 2010).

Each sensor can be described in terms of its $N_{0}$, the reference dry counting rate at a reference location and environmental condition. That is the number of counts adjusted for location and pressure devoid of hydrogen interaction, a corrected baseline count rate. As the count rate increases from this baseline, the instrument is detecting higher amounts of hydrogen within its sensing footprint. The $N_{\mathrm{o}}$ is instrument specific, relatively invariant, and based upon sensor size and configuration and is determined 
experimentally. Minor variance exists in an instrument's effective $N_{0}$ due to changes in internal position, carrying vehicle configuration, but the theoretical $N_{o}$ should be constant for any individual instrument.

This number devoid of hydrogen interaction can be described as the ideal $N_{\mathrm{o}}$, the ideal $N_{\mathrm{o}}$ is instrument specific and unchanging. In reality, hydrogen pools are plentiful, and only the most significant are accounted for, primarily atmospheric and soil water. The real $N_{\mathrm{o}}$ for any campaign is determined by the available information to disaggregate the signal in processing. As more hydrogen pools are removed, the real $N_{0}$ approaches the ideal $N_{\mathrm{o}}$ :

$$
N_{\text {oreal }}=N_{\text {oideal }}+\omega_{\text {lat }}+\rho_{\text {oc }}+\beta_{w}+\beta_{d}+\cdots
$$

where $w_{\text {lat }}$ is the soil lattice water $(\mathrm{g} / \mathrm{g})$ and $\rho_{\text {oc }}$ is soil organic carbon $(\mathrm{g} / \mathrm{g})$ and $\beta_{w}$ is wet biomass while $\beta_{d}$ is dry biomass, both $\left(\mathrm{kg} / \mathrm{m}^{2}\right)$. The relationship between the neutron counts and soil moisture can then be described by the $N_{0}$ calibration function from (Desilets et al. 2010):

$$
\theta\left(N_{c o r}\right)=\frac{a_{0}}{\left(\frac{N_{c o r}}{N_{0}}\right)-a_{1}}-a_{2}
$$

Where $a_{i}$ are constants (0.0808, 0.372, and 0.115 in order) defined (Desilets et al. 2010), $N_{\mathrm{o}}$ is the dry counting rate at a spatio-temporal reference, and $N_{c o r}$ is the corrected counting rate. The variables of lattice water, soil organic carbon, and bulk density, if known, can be included here to produce

$$
\theta\left(N_{c o r}\right)=\left(\left(\frac{a_{0}}{\left(\frac{N_{c o r}}{N_{0}}\right)-a_{1}}-a_{2}\right)-\left(\omega_{\text {lat }}+\rho_{\text {oc }}+\cdots\right)\right) \rho_{b}
$$

where $\rho_{b}$ is the soil bulk density ( $\mathrm{g} \mathrm{cm}^{-3}$ ) (Dong et al. 2014). Additional hydrogen pools may be added in a similar manner if known but should also be accounted for in analysis. Lattice water will have little variability over a local area and as such can be safely assumed for most purposed to be uniform over a kilometer scale, moderately homogeneous area. Soil organic carbon and soil bulk density may be more variable depending on land use. 
The variable, $N_{\mathrm{o}}$, as mentioned earlier, is the dry counting rate and is determined experimentally through inversing the $N_{o}$ calibration function (Equation 3).

$$
N_{0}=\frac{N_{c o r}}{\left(\frac{a_{0}}{\theta+\omega_{l a t}+\rho_{o c}+a_{1}}\right)+a_{2}}
$$

Surface soil moisture is measured during calibration through a sampling of gravimetric soil water, which may be combined with surface proximal sampling methods such as time-domain or frequency-domain reflectometry. Lattice water and soil organic carbon are obtained through laboratory analysis of soils. This calibration is ideally done before any new campaign but should be fairly robust for transportation needs without re-calibration as mentioned, the $N_{0}$ should be relatively invariable.

\section{Corrections and calculations for COSMOS}

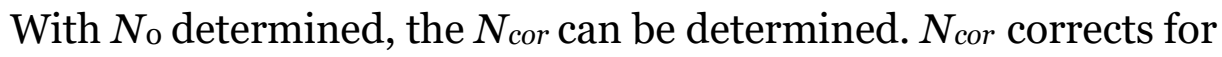
variation of neutron intensity, barometric pressure, and atmospheric water vapor. These corrections effectively bring $N$, the raw counts, back to the conditions of calibration when $N_{0}$ was determined (or other spatiotemporal reference).

The sum of corrections can be defined as (Zreda et al. 2012; Vather et al. 2019)

$$
N_{c o r}=N \times f_{w v} \times f_{p} \times f_{i}
$$

where $N$ is the raw counts, $f_{w v}$ is the water vapor correction, $f_{p}$ is the correction for elevation-based neutron intensity as a function of barometric pressure, and $f_{i}$ is a function of neutron intensity due to temporal variation.

The correction for atmospheric water vapor developed by (Rosolem et al. 2013) is

$$
f_{w v}=1+0.0054 \times \Delta_{p v}
$$

where $\Delta_{p v}$ is the difference between measurement humidity and the reference humidity, most often the reference calibration humidity. 
The barometric pressure correction is actually a correction for elevationbased attenuation based on the cutoff rigidity of high-energy neutron in the planets magnetic field. Pressure acts as a proxy for elevation where again the difference in pressure between a reference point $\left(\mathrm{P}_{0}\right)$ and the current measurement $(\mathrm{P})$ is identified.

$$
f_{p}=\exp \left(\frac{P_{0}-P}{L}\right)
$$

$L$ is the mass attenuation length in $\mathrm{cm}^{2} / \mathrm{g}$ and can be approximated at $128 \mathrm{~cm}^{2} / \mathrm{g}$ when latitude is greater than 70 degrees and when less than 70 degrees latitude $(l)$ :

$$
L=142-(0.2 * l)
$$

Attenuation length can be more accurately estimated via COSMOS utility at http://cosmos.hwr.arizona.edu/Util/rigidity.php as the gradient is not in truth directly related latitude (Figure 2), but the approximation may be made in conditions of diminished connectivity.

Figure 2. Vertical cutoff rigidity for 1980 from (Desilets et al. 2006). Vertical cutoff rigidity and attenuation length are linked and therefore exhibit the same field characteristic.

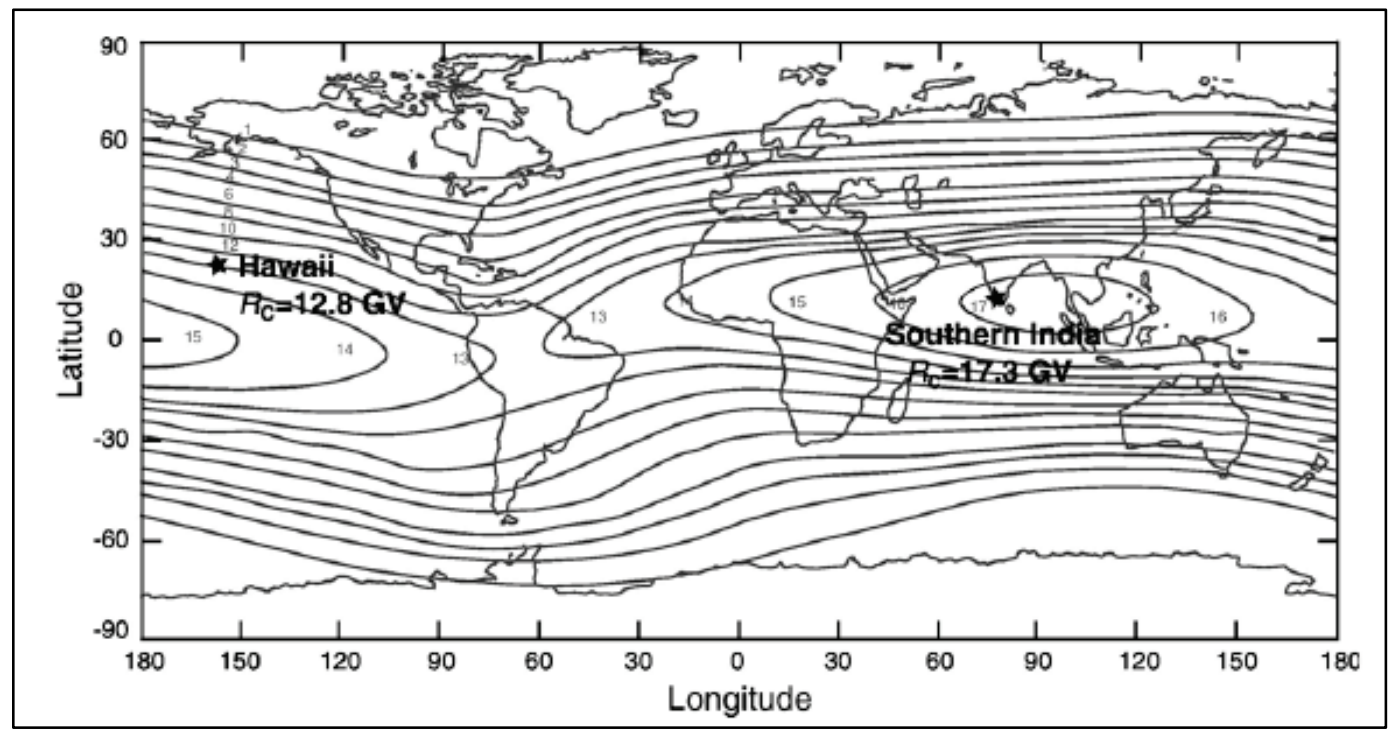


The neutron intensity correction factor is a simple scaling ratio of incoming cosmic radiation intensity of the reference date and the measurement date.

$$
f=\frac{I_{m}}{I_{0}}
$$

Neutron intensity can be obtained from the neutron monitor database (www01.nmdb.eu/nest/). While it is preferable to obtain readings from a station with a similar cutoff rigidity, cosmic rays are exogenous to the planet and should be relatively consistent in scaling increases and decreases across all stations (Andreasen et al. 2017). For the analysis, the neutron monitors at Jungfraujoch at Sphinx observatory in Switzerland were used, provided by the Cosmic Ray Group, Physikalisches Institut, University of Bern, Switzerland at http://cosray.unibe.ch.

\section{Vegetation-based corrections}

The biomass signal is generally relatively small compared to the total water signal in COSMOS data (Franz et al. 2015). During calibration, the $\mathrm{N}_{\mathrm{o}}$ signal is determined as though it were devoid of any vegetation signature, removed through sampling of biomass. This occurs through subtraction of the signal based on total estimated volume within the footprint of the calibration. Studies have shown a linear relationship of approximately a $1 \%$ drop in $\mathrm{N}_{\mathrm{o}}$ for each $1 \mathrm{~kg} / \mathrm{m}^{2}$ of biomass above ground (Franz et al. 2015; Baatz et al. 2015). These studies further demonstrated that the signal within cereal crops, short grasslands, and legumes are too small to be differentiated from the noise. However, maize, and soybean contain a significant enough signal to be corrected (Franz et al. 2018).

This correction of standing biomass (biomass water equivalent, BWE) can be described in terms

$$
B W E=a+b * M+c * \frac{M}{B}
$$

where $\mathrm{a}, \mathrm{b}$, and $\mathrm{c}$ are locally derived variables, $\mathrm{M}$ is corrected neutron counts, and B is the bare counts from the COSMOS (Franz et al. 2018). A secondary form of the BWE equation can be determined from standing wet (SWB) and dry (SDB) biomass as

$$
B W E=S W B-S D B+S D B * f_{W E}
$$


where $f_{\mathrm{WE}}=0.494$, the ratio of organic carbon to water in cellulose (Franz et al. 2018). However, for the growing season in the test region, significant biomass does not really begin to accumulate in either maize or soybean until late June and early July, respectively. In this case, correction of vegetation for agricultural fields was ignored.

For forested region, typical biomass estimates for the endemic forest type to this region might be used. In this region of north central Iowa, it is an Oak-Poplar-Basswood-Maple configuration. Reviewing estimates of standing live and dead tree mass, there can be an estimate of total biomass for Northern Prairie forests of these types to be averaged to approximately $150 \mathrm{Mg} / \mathrm{ha}$ while standing dead tree biomass is negligible (Smith et al. 2003). This converts to $15 \mathrm{~kg} / \mathrm{m}^{2}$ from which water content can be estimated using the rough guide of 50\% dry biomass to water. Then, it is possible to estimate the woodlands of this region on average have a water content of approximately $7.5 \mathrm{~kg} / \mathrm{m}^{2}$ or a reduction of volumetric water content of $0.01 \mathrm{~m}^{3} / \mathrm{m}^{3}$.

\subsection{Objective}

The objective of this research is to evaluate and demonstrate the potential of vehicle-mounted sensors to improve the real-time prediction of vehicle cross-country mobility. The goal is to use weather-based forecasts of soil strength as the initial estimate for cross-country mobility and blend the data obtained from vehicle-mounted sensors using advanced data assimilation techniques to update and provide more accurate assessments of area risks to vehicle maneuver. This augmented terrain data will provide an improved basis for mobility modeling and autonomous-driver decision making. This specific study explores the feasibility of using one specific type of on-board soil moisture sensor to update a linked predicted weather-and-mobility model combination and describes the evaluation of the sensor measurements compared to both in situ observations and a land-surface model-based gridded soil moisture product.

\subsection{Approach}

Prior to developing the routines to assimilate COSMOS observations into the GeoWATCH, an evaluation of the individual datasets was needed along with how well each dataset was correlated to each other. This initial data assessment determines the feasibility of assimilation to make sure the differing data types are correlated, measure similar quantities, do not 
contain significant quantities of random error, and offer potential to be blended together to generate a more accurate assessment of environmental conditions. The approach to evaluating the feasibility of the concept was to complete a comparison between a vehicle-mounted soil moisture sensor (Cosmic-ray Soil Moisture Observing System [COSMOS]) and a weather-based estimate of soil moisture (Geospatial WeatherAffected Terrain Conditions and Hazards [GeoWATCH]) using previously collected COSMOS observations during the SMAPVEX16 field study, compare the COSMOS measurements and GeoWATCH produced results to in situ soil moisture measurements from the field study, and determine whether the datasets were correlated to each other. This study resulted in a Python-based software reader to process the raw data counts from the COSMOS sensor to compute soil moisture estimates. The resulting data were evaluated for quality, filtered according to terrain conditions and other environmental concerns. Additionally, a software routine was developed to upscale the GeoWATCH data from $30 \mathrm{~m}$ to resolutions matching the COSMOS observations for the comparison. This report describes that approach and summarizes the evaluation of the COSMOS and GeoWATCH datasets and provides an evaluation of the assessment of potential for using the COSMOS sensor data to dynamically update a mobility modeling prediction. 


\section{Methods}

\subsection{Integration of locally sensed data with exogenous spatial data}

Operating in the tactical environment requires systems to minimize data transfer requirements. While the aforementioned methods of proximal sensing indicate soil conditions near the vehicle, the end goal is to extrapolate this near-vehicle information to the wider operations area.

While in drier environments, strength tends to be driven by textural components such as the internal angle of friction and total clay content; wetter environments are more difficult due to the complexity of the surface interactions and multiple inferences that must be made to estimate surface conditions. Remote sensing signals often become somewhat obscured due to vegetation and or cloud cover. It is therefore in the most marginal regions of travel that there is the least information. The COSMOS and microwave signals of opportunity become increasingly important in these areas due to the paucity of other information. Information from these sensors in the area of operation can be used to update predictions generated by coupled, weather-driven land surface models. The sensor data can be used both to flag areas that are not well represented by the predictive methods and to compute more accurate estimates of the greater operating region's ground conditions.

A land surface model is used to compute the terrestrial hydrology and energy mass budget equations and parameters within both the LIS and GALWEM modeling systems. In addition to updating those predictions in real time, COSMOS observations could also be used in research and model evaluation and benchmarking in verification and reanalysis for more accurate site strength estimation.

For this project, a Python-based software application was developed to compute soil moisture measurements based on the raw data generated from the COSMOS data logger. The COSMOS neutron counts, location information, and other quality-check information were combined with regional maps of soil, vegetation, and local weather observations within the application to compute soil moisture estimates and compare with a previously developed spreadsheet computation as a double check on computational accuracy. Geospatial maps of soil texture information came from the USDA State Soil Geographic Database Web Soil Survey 
(USDA/NRCS Soil Survey Staff) while vegetation information came from the US Geological Survey 2016 National Land Cover Database (NLCD) (Homer et al. 2020; Yang et al. 2018; Jin et al. 2019). Additionally, surface air temperature and relative humidity observations were obtained from the National Centers for Environmental Information archive. Ideally, a vehicle equipped with a COSMOS rover would include an on-board, external temperature and humidity sensor; however, that was not available for this study.

A significant amount of time was also devoted to developing a spatial footprint matching algorithm between the GeoWATCH observations and the COSMOS data, using the geospatial terrain layers to filter out observations in urban environments or around bodies of water (lakes/streams). The spatial matching is required to ensure the coarserresolution COSMOS observations, as described in section 2.4.2.1, can be properly evaluated against the higher-resolution GeoWATCH model estimates. Those spatial filtering and aggregating methods described below relied upon the same $30 \mathrm{~m}$ resolution STATGO and NLCD datasets previously described.

The data analysis for this project was conducted using both Python software written to support this project and the Free and Open-Source Geographic Information System software package, QGIS, obtained from https://www.qgis.org, version 3.12.2-Bucuresti. Available Web Mapping Service layers available in QGIS were used, including the Google Satellite, Open Street Maps, and Google Maps Labels only within the evaluation and/or display of results.

\subsection{Study domain and data}

The area represents approximately $840 \mathrm{~km}^{2}$ in the north central part of Iowa, with the town of Iowa Falls, IA, in the eastern part of the domain representing the largest urban center and the rest of the domain characterized primarily by agriculture (Figure 3). The domain consists of parts of four counties: Hamilton, Franklin, Wright, and Hardin. There are two highways that cross through the area, including the north-south interstate (I-35) and US Highway 20 stretching east-west across the southern part of the study domain. Additionally, there are many paved and unpaved roads arranged in a grid-like pattern across the entire study region. The roads are a mixture of either primary roadways constructed with concrete or asphalt paving. The many farm roads that make up the grid structure are dirt-gravel blends. 
Figure 3. Google Earth image with road network overlay image of the study domain surrounding lowa Falls, IA. The black dots with labels are locations of in situ soil moisture probes placed as part of the SMAPVEX16 project.

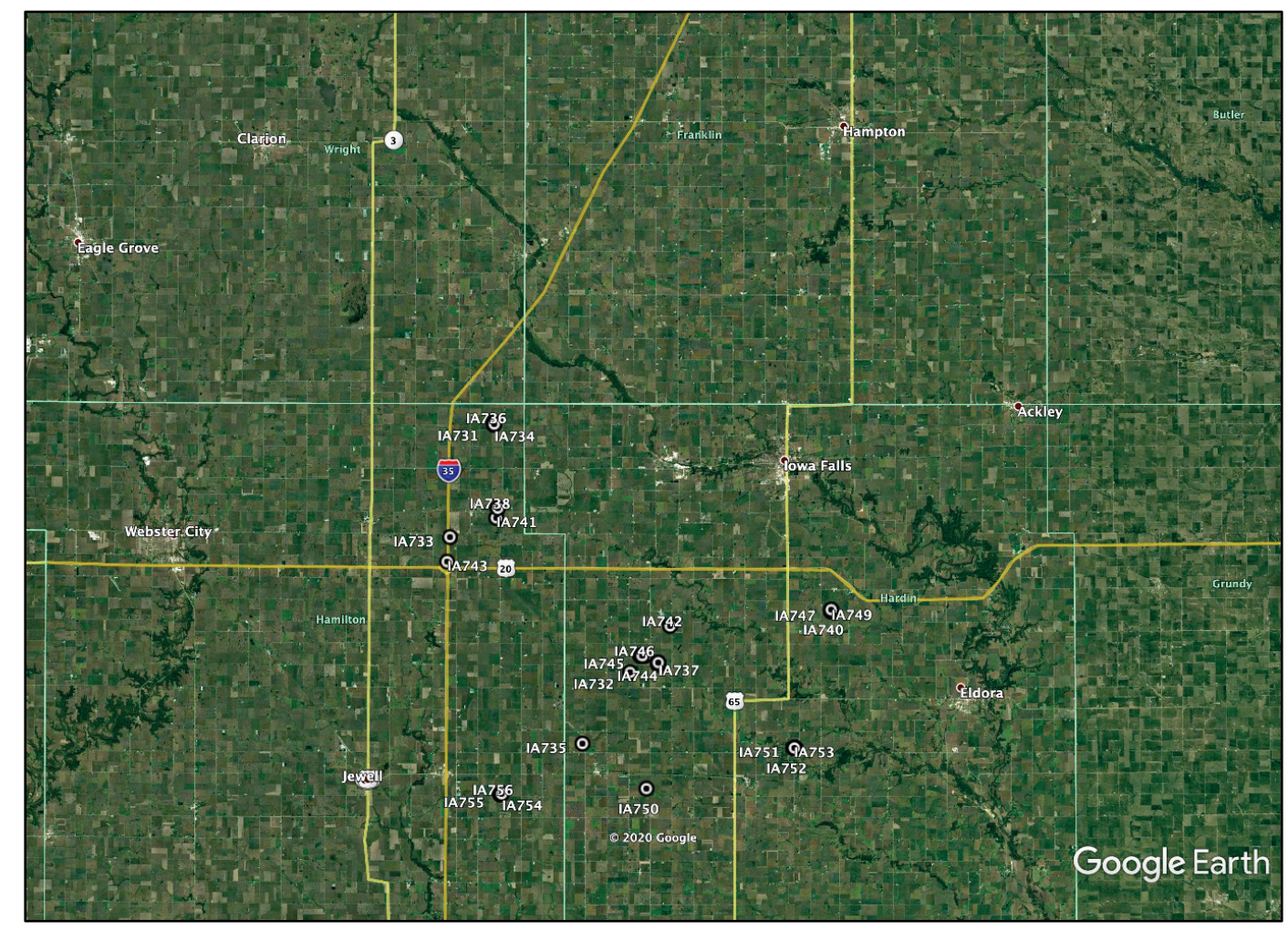

The Iowa River flows southeast through the domain, depicted in light blue on the map (Figure 4) stretching from the upper left corner through the center of the map and exiting the lower right. The second stream along the bottom of the map is the South Fork Iowa River. Figure 4 contains a representation of the ERDC COSMOS rover observations in the domain overlaid on an OpenStreetMap graphic of the domain. The relative size of the circles in Figure 3 represent an estimate for the area the COSMOS rover is observing, and the location colors represent the volumetric soil moisture ranging from dry conditions (dark brown) through moist conditions (darker green). Red circles identify locations where the COSMOS observations were in the vicinity of a water body (within the $240 \mathrm{~m}$ radius measurement location center point) as identified in the NLCD and were therefore excluded from the analysis. The smaller black circles in Figure 3 (above), labeled with identifiers beginning with IA plus a three-digit number (e.g., IA 752), represent locations of in situ soil moisture probes deployed as part of the SMAPVEX16 project. 
Figure 4. Map of the study domain with colored circles representing the COSMOS observation. A distance scale bar is located in the upper left of the image for reference. The red colors represent omitted observations. The brown-to-green circles are valid observations representing dry-to-wet estimates from COSMOS. A reference color bar is in the lower right corner.

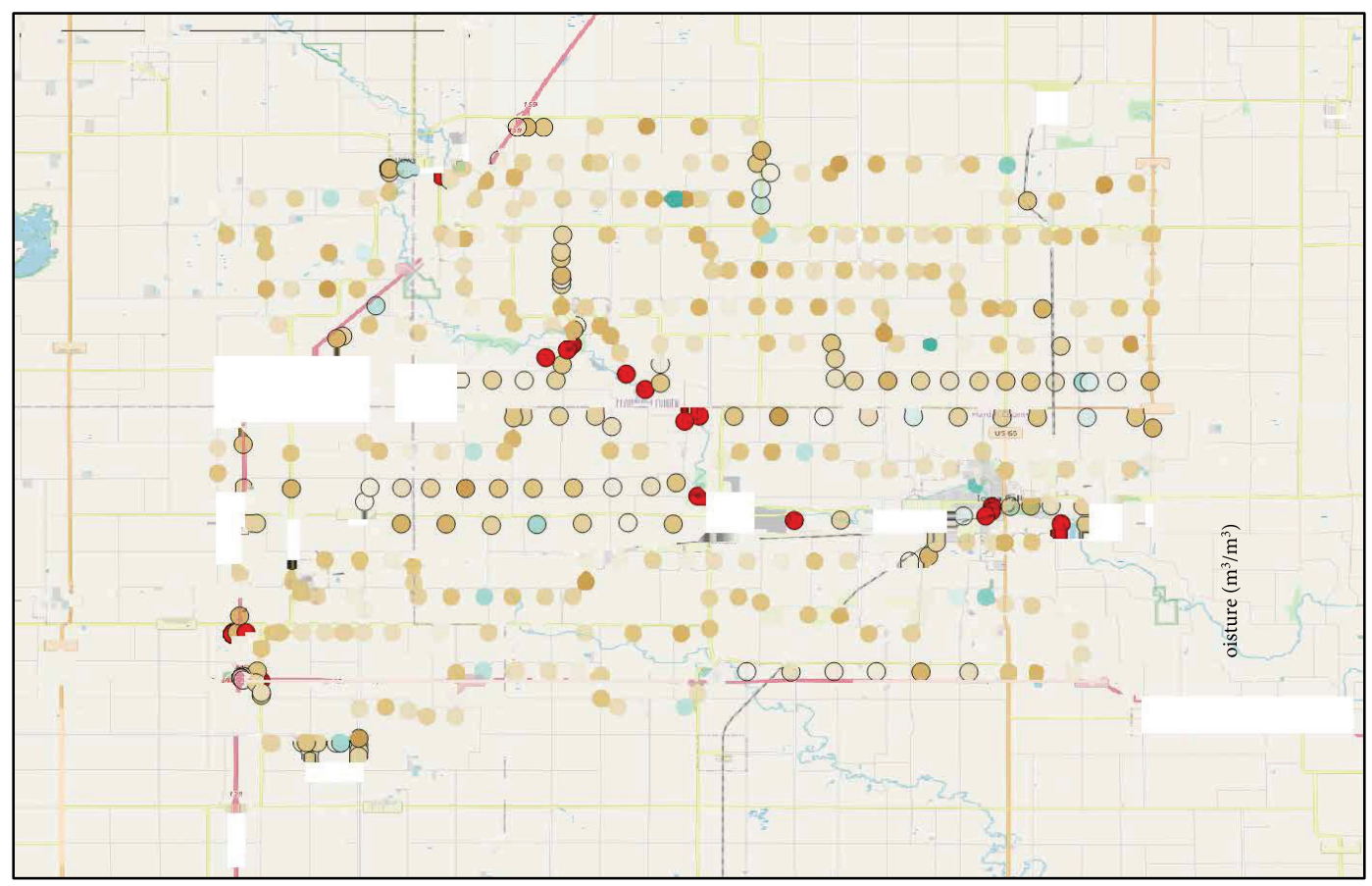

The NLCD characterization of the domain describes the area as consisting of large areas of cultivated crops, appropriate given that this area is primarily characterized by farms. The roads and regions in/near towns are identified as developed but make up a very small percentage of the domain. There are also small areas of mixed forest and pasture/hay. Soils in the region are classified primarily in two Soil Stage Geographic classes, loam and silty clay loam. The USDA Soil Survey Geographic Database soil taxonomy further breaks the soils into a mix of loam, clay loam, and silty clay loams, along with some silt loam soils spread throughout the domain and sand and loamy sand near the river (Figure 5) (Soil Survey Staff, Web Soil Survey 2019). 
Figure 5. Study domain maps of USGS Land Use Classification map (left) and USDA

Soil Texture classification map (right). The land use is primarily categorized as cultivated according to the NLCD 2016 data (blue colors) with some urban (red), forest (green colored areas) and water. The soils are primarily loams (white color) with some silty clay loam (blue) and silty (brown) soils.

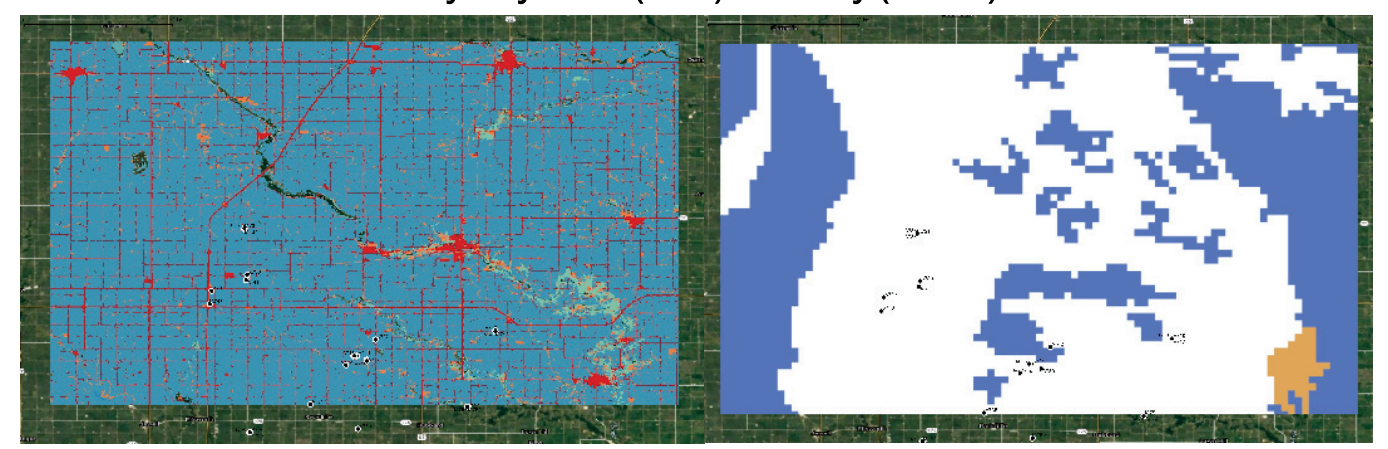

The area weather conditions for 29 May 2016 observational period were cloudy with a diurnal temperature range from low $60 \mathrm{~s}^{\circ} \mathrm{F}$ to the upper $70 \mathrm{~s}^{\circ} \mathrm{F}$. Dew points were approximately $60^{\circ} \mathrm{F}$ in the morning then falling slowly over the course of the day to $55^{\circ} \mathrm{F}$. There were spotty light showers in the area, with National Weather Service observation site at Iowa Falls reported 0.10 in. of precipitation on this date, and a Community Collaborative Rains, Hail and Snow Network (Cifelli et al. 2005) observation available from a location in the northeast part of the domain reported .04 in. of precipitation. The Clarion, IA, automated weather observation recorded $5 \mathrm{~mm}$ of rain at 19:55 local time. Weather observations from automated observation systems in Webster City and Waterloo, IA, reported no precipitation during the day. Winds were out of the west in the morning between 10 and $15 \mathrm{kn}$ gusting to between 15 to $20 \mathrm{kn}$, decreasing during the afternoon and becoming light and variable.

\subsection{Cosmic-ray Soil Moisture Observing System (COSMOS) rover observations}

During rover observation collection operations, the operators started the day parked in one location for the first $15 \mathrm{~min}$ of the traverse recording a number of observations from the same location in which to calibrate the sensor. The rover was operated starting at approximately o9oo local morning time (1400 UTC) then driven throughout the domain on both paved and unpaved roads obtaining measurements that were output to a comma separated values (CSV) file by the COSMOS data logger that contained information about the latitude and longitude from each observation, along with altitude, temperature, humidity, vehicle speed, and the neutron counts from the pair of tubes. At the end of the 
observation period, at approximately 23:30 UTC, the rover was also parked in one location taking measurements. A plot of the raw neutron counts for each sensor is included in Figure 6. The soil moisture computation produced by the Python application written for this project, using Equations 1-10 (presented previously) to convert the raw neutron counts into volumetric soil moisture and including correction factors adjusting the neutron counts to account for the atmospheric pressure, atmospheric humidity and altitude, is the top plot in Figure 6. The temperature and relative humidity measurements that were part of the CSV file were using sensors inside the vehicle and were omitted and replaced with the values from the Iowa Falls airport reporting location using a spreadsheet-based curve-fitting algorithm.

The resulting volumetric soil moisture observations produced by the algorithm are displayed as a histogram and are presented on a map in Figure 7. The COSMOS observations produce a range of soil moisture estimates from .08 to $.53 \mathrm{~m}^{3} / \mathrm{m}^{3}$, with a mean value of $0.17 \mathrm{~m}^{3} / \mathrm{m}^{3}$ and a standard deviation of .09 $\mathrm{m}^{3} / \mathrm{m}^{3}$. The histogram plot of the COSMOS data illustrates that a majority of the observations are between 0.1 and $0.26 \mathrm{~m}^{3} / \mathrm{m}^{3}$. 
Figure 6. Raw neutron counts from the (a) N1 and (b) N2 sensors in the ERDC COSMOS rover along with the temperature (c) and resulting computed soil moisture (d).

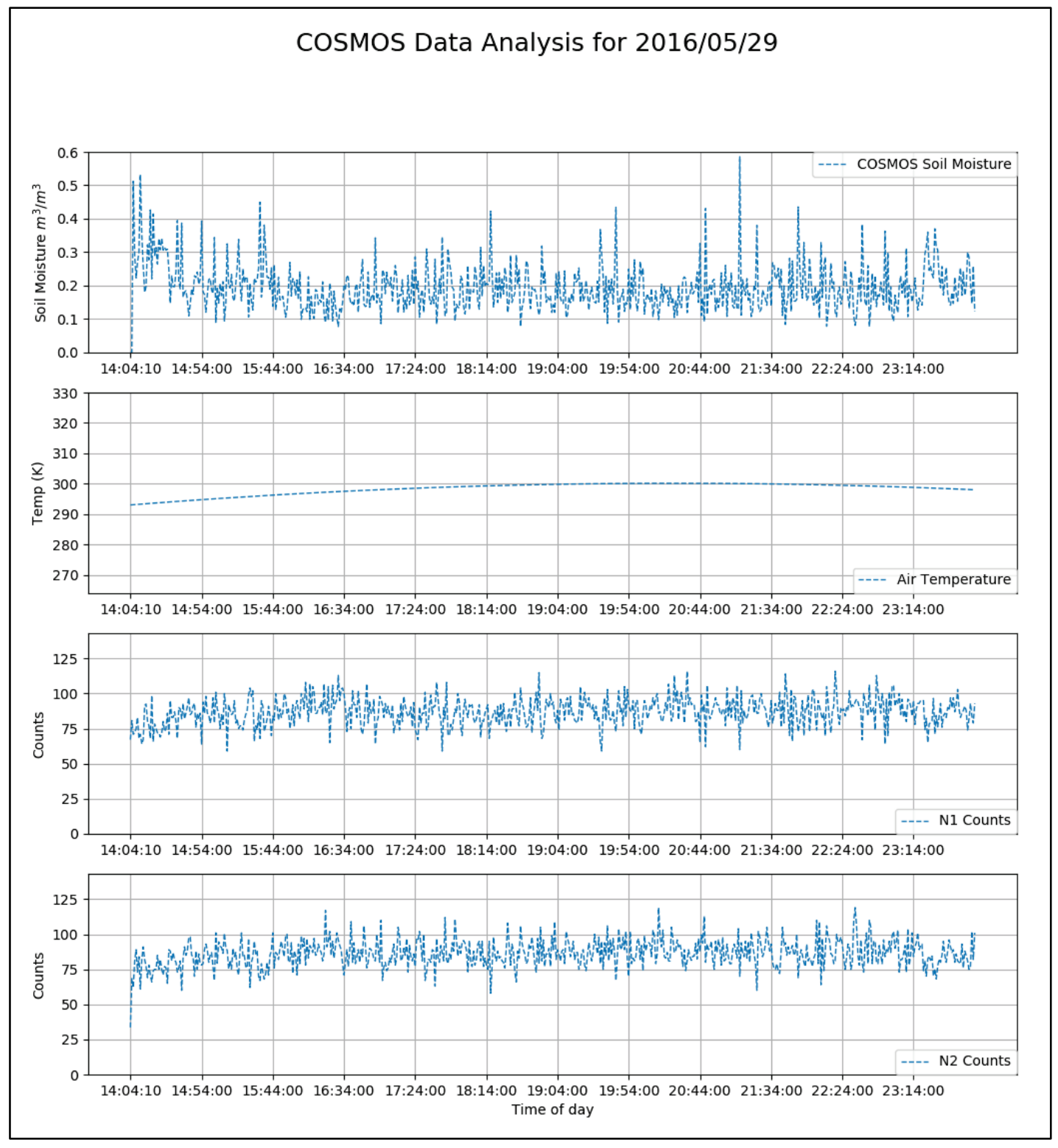


Figure 7. Histogram of the ERDC COSMOS rover volumetric soil moisture estimates (left) and the map of the rover observation (right) with colors representing the computed volumetric soil moisture estimate.

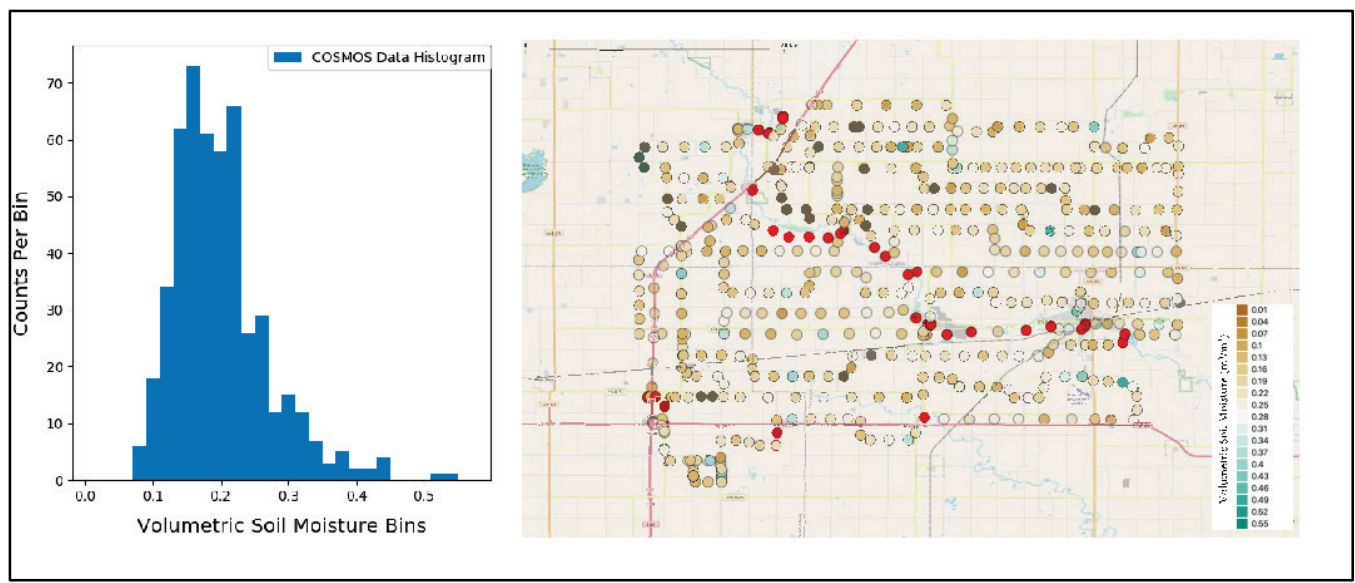

\subsection{GeoWATCH soil moisture data}

For this exercise, GeoWATCH products were downloaded from the website using a WCS protocol in GeoTIFF format and imported into QGIS for evaluation and read directly into the Python routines for computational analysis and comparison with the in situ observations and COSMOS data. Volumetric soil moisture for an approximate $4150 \mathrm{~km}^{2}$ area was obtained on a raster grid with dimensions of $2085 \times 1633$, representing a slightly larger region than the COSMOS rover route (Figure 8). The GeoWATCH observations were initially retrieved for a single time period, 29 May 2016, 18 UTC. The range of soil moisture conditions for the GeoWATCH data for the entire domain is 0.08 to 0.48 representing a wide range of wetness values across the domain. Later, the Python routine was modified to retrieve observations from the 15 UTC, 18 UTC, 21 UTC, and oo UTC from May 30 so that the comparisons between GeoWATCH and COSMOS would include a time-of-day consideration. The COSMOS and GeoWATCH soil moisture data were then matched in time using the observation time of the COSMOS data matching the closest GeoWATCH analysis time. 
Figure 8. GeoWATCH volumetric soil moisture analysis valid 29 May 2016 at 18 UTC with overlayed an Openstreet map. Included are the ERDC COSMOS rover observation locations (colored circles) and the locations of in situ soil moisture observations (black circles). Red circles represent COSMOS observations that were omitted from comparison due to the proximity of water near the observation or because the observation was taken primarily in area classified as urban or dense urban by the NCLD 2016.

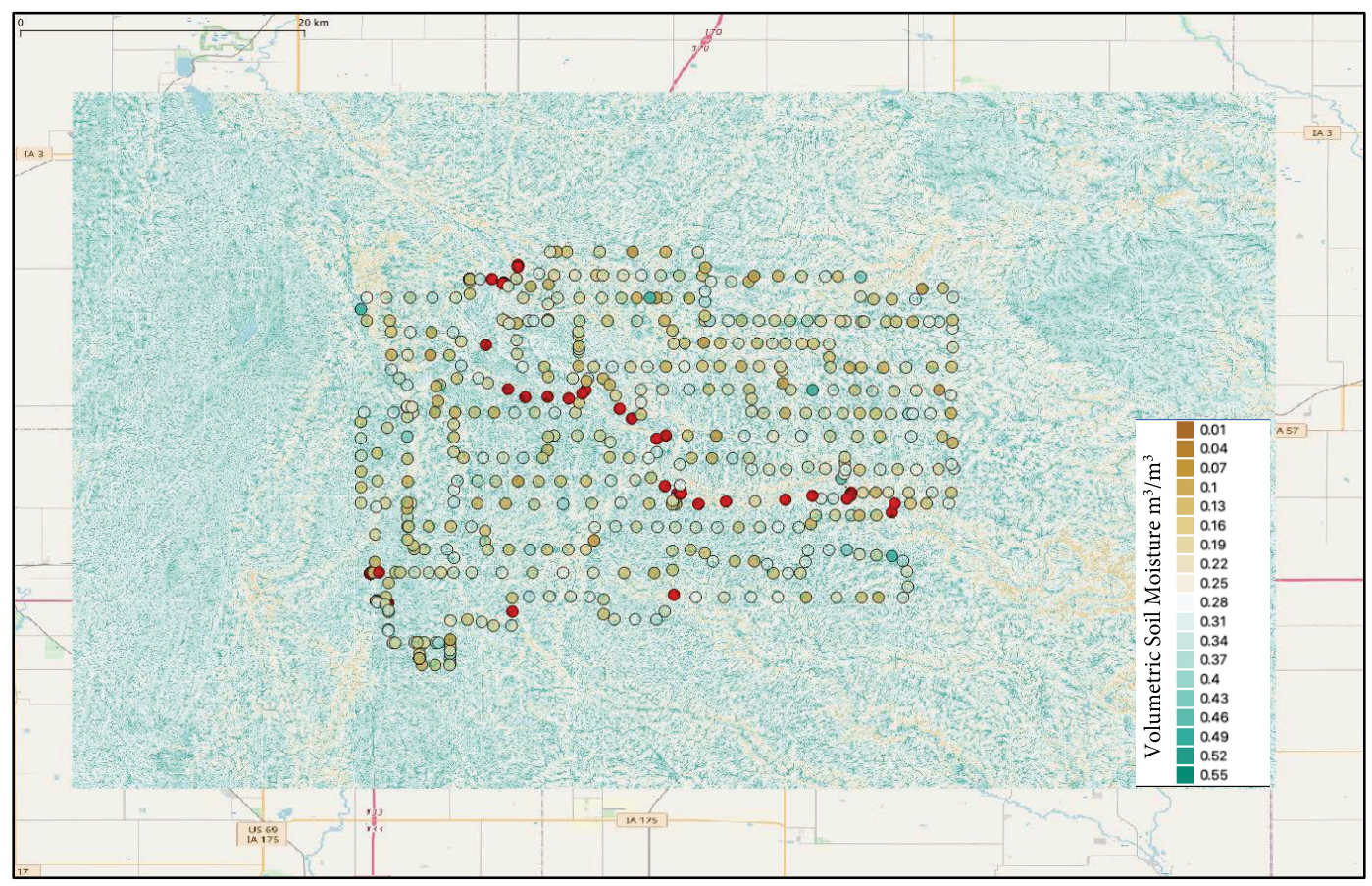

\subsection{COSMOS-GeoWATCH spatial matching methods}

Accurately comparing a model-produced estimate of soil moisture produced on a regular grid to a remotely sensed observation that represents a variable volume of soil depending on the water content is challenging. In the case of this project, the COSMOS observations represent a larger spatial area $(\sim 600$ m diameter $)$ than the GeoWATCH observations ( $3-90 \mathrm{~m}$ resolution) making it necessary to develop a method to aggregate the GeoWATCH data to better match at least the horizontal area of the COSMOS observations. However, the COSMOS spatial measurement is heavily weighted toward soil water within the first $60 \mathrm{~m}$ of distance from the sensor, especially in wet soil conditions (Kohli et al. 2015). Additionally, a majority of the COSMOS soil moisture measurement is in the top $10 \mathrm{~cm}$ of the soil though the relationship varies based on soil wetness, vegetation, and other factors. The intensity of the cosmic energy received by the sensor can be described on a logarithmic decay curve (Kohli et al. 2015), which were used to describe a weighting function to compute the area average soil moisture for the GeoWATCH 
data. The footprint match used a logarithmic distance-weighting approach based on the average energy response (average of the dry and wet energy curves) from Kohli et al (2015) for COSMOS observations. Once the average of the wet and dry intensity values was estimated, a curve-fit algorithm was used to generate an equation used to compute the grid cell weighting values (Figure 9). The weights for each grid cell were normalized using the equation computed in the previous step on a scale from 0 to 1 , with 1 representing the locations closest to the center of the grid and values in the corners of the grid of 0.05 .

After the weighting grid was computed, the latitude and longitude from the COSMOS measurement location was used as recorded in the data logger to estimate the center grid cell of the associated GeoWATCHmatched array. From that point, an array was selected based on eight, 30 $\mathrm{m}$ grid cells in each direction representing a $240 \mathrm{~m}$ radius along the $\mathrm{x}$ - or $\mathrm{y}$-directions in a grid-based format as a $16 \times 16$ array of data, as shown in Figure 9(b). The array of weights previously computed to compute the weighted average of soil moisture for the entire $16 \times 16$ grid for each COSMOS measurement location was applied.

Figure 9. a) Graph of weighting function with distance; b) the resulting $16 \times 16$ array of relative weights computed for the GeoWATCH data.

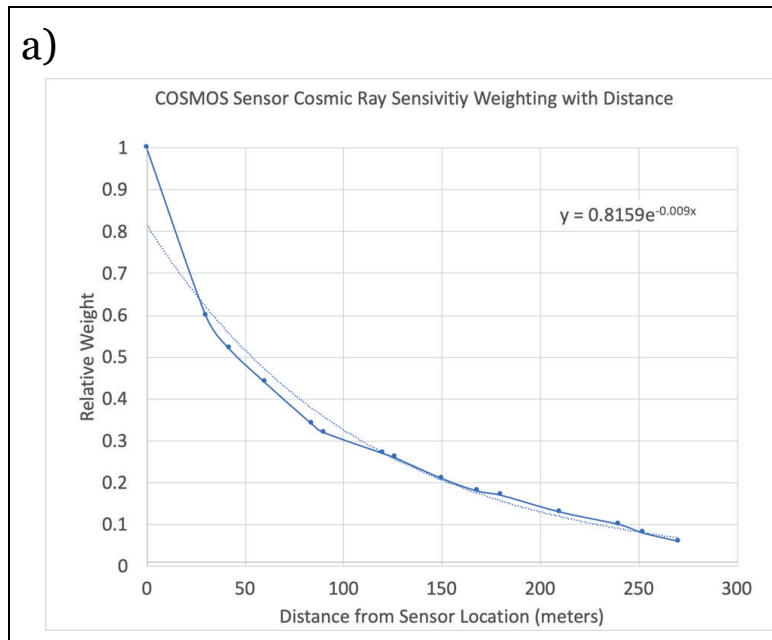

b)

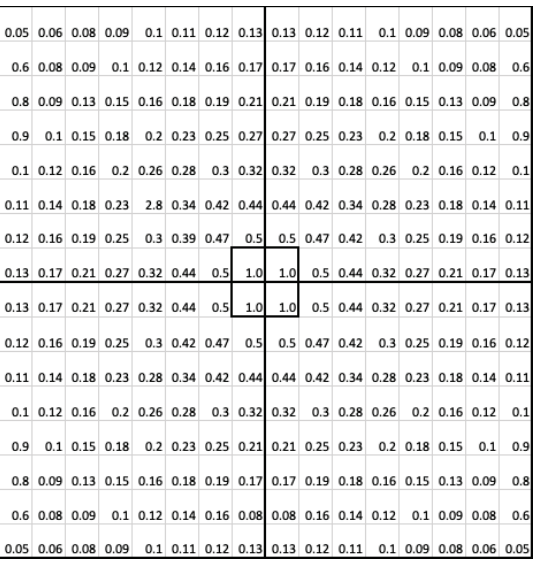




\subsection{COSMOS rover observation filtering}

The COSMOS measurements constitute an indirect, remotely sensed assessment of soil moisture in the area around the sensor, but not all of the energy received by the sensor is produced only by water from soil moisture. As the sensor is driven around, some measurements may include energy coming from lakes and ponds, streams, or other sources of hydrogen in the vicinity, including hydrocarbons from stored fuel (Adreasean et al. 2017). During the initial comparisons and data analysis of both the COSMOS and GeoWATCH, a number of significant differences were identified between the COSMOS observations and GeoWATCH model products near surface water locations (streams and ponds). The large differences between the two datasets significantly impacted the initial correlation computation, leading to the introduction of one of several filters within the analysis. For this initial evaluation, a simple landuse water identification filter was developed, using the NLCD 2016 to identify any water body within the area of the COSMOS measurement. If a water body was present, the COSMOS observation was set to zero. After filtering out water sources, the comparisons between the two datasets produced a correlation value of 0.65 , a significant improvement over initial values that were either very close to zero or slightly negative. The COSMOS observations that were filtered out are highlighted in Figure 8 with a red circle. For the statistical comparisons, both the COSMOS and GeoWATCH locations identified as containing water points were removed from the dataset prior to computing statistical correlations for locations with surface water bodies in the measurement footprint.

The initial evaluation of the COSMOS soil moisture observations in a GIS system, compared to GeoWATCH, presented strong disagreement between the two datasets in regions that could be identified as an urban land classification. It is believed that some of the impact could be hydrocarbon sources from stored fuels, irrigated lawns, or other sources commonly found more in urban settings than they are in more rural environments. Additionally, since the goal of this comparison was to determine the feasibility of blending the two datasets to support cross-country mobility, an operation not common in a built-up environment, it was decided to mask out the measurements obtained in urban areas again using the urban classification in the NLCD 2016 data.

Additionally, after the initial evaluation of the data was conducted against a single GeoWATCH analysis time, a time-based comparison was 
developed that used the observation time from each COSMOS measurement to select the closest GeoWATCH analysis time for the comparison. Since the COSMOS measurements started shortly after 14 UTC on 29 May 2016 and ended shortly before oo UTC on 30-May-2016, four increments of GeoWATCH analyses were matched to the COSMOS measurements. The matching occurred based on the date/time proximity; the COSMOS measurements were matched to the closest GeoWATCH analysis time for the $15,18,21$, and oo UTC cycle times based on a simple subtraction-based minimization algorithm. The resulting comparisons make sure the COSMOS data are compared to the closest GeoWATCH estimate in time, and that time is not a factor in any statistical disagreement between the two datasets. 


\section{Discussion}

Figure 10 is a plot of the COSMOS rover and GeoWATCH weighted average volumetric soil moisture estimates with time. Looking at the GeoWATCH analysis for those locations where the COSMOS measurements were taken produces a much narrower range of soil moisture observations, from 0.25 to $0.36 \mathrm{~m}^{3} / \mathrm{m}^{3}$.

Figure 10. Volumetric soil moisture estimates from the COSMOS rover (blue crosses) and the GeoWATCH weighted average (orange dots) vs. time.

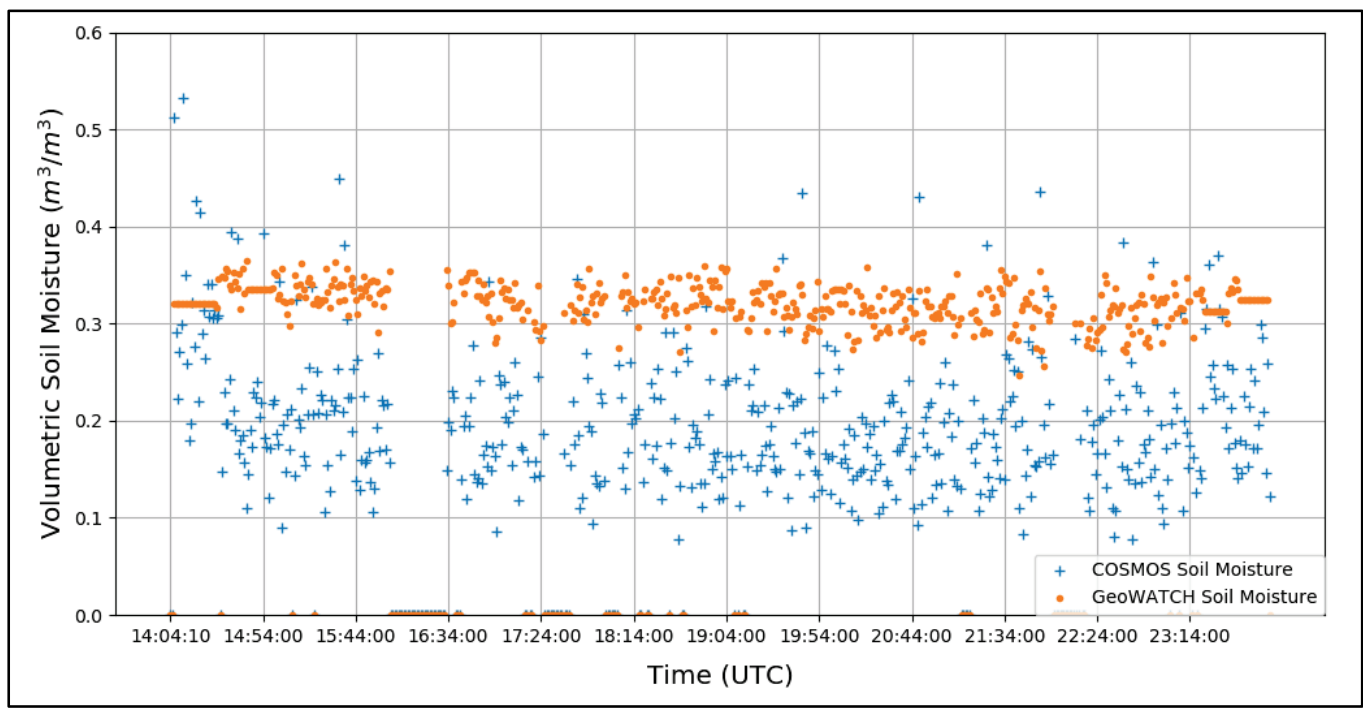

The COSMOS measurements and the GeoWATCH soil moisture estimates have a positive correlation with a resulting Pearson's correlation coefficient of 0.75 after accounting for all the time, space, and location filtering on both the COSMOS and GeoWATCH data. Overall, the COSMOS soil moisture values are considerably lower than the GeoWATCH-matched estimates, with the mean of the datasets being 0.16 $\mathrm{m}^{3} / \mathrm{m}^{3}$ and $0.27 \mathrm{~m}^{3} / \mathrm{m}^{3}$, respectively. The range of the measurements from the COSMOS probe is broad, ranging from 0.08 to $0.53 \mathrm{~m}^{3} / \mathrm{m}^{3}$, and compared to the range for the GeoWATCH-matched estimates is 0.25 to $0.36 \mathrm{~m}^{3} / \mathrm{m}^{3}$. While the data are correlated statistically, there is large overall trend that the GeoWATCH results are generally higher and narrower in measured range of soil moisture values than the COSMOS measurements (Figure 11). The range of the entire grid of GeoWATCH soil moisture estimates is 0.094 to $0.476 \mathrm{~m}^{3} / \mathrm{m}^{3}$ (Figure 12). 
Figure 11. Scatter plot of COSMOS rover soil moisture estimates plotted against weighted GeoWATCH soil moisture analyses. The rover observation time is considered in the GeoWATCH weighted averaging, making the weighted average a compilation of GeoWATCH analysis times from 15 UTC 29-May-2016 to 00 UTC on 30 May 2016.

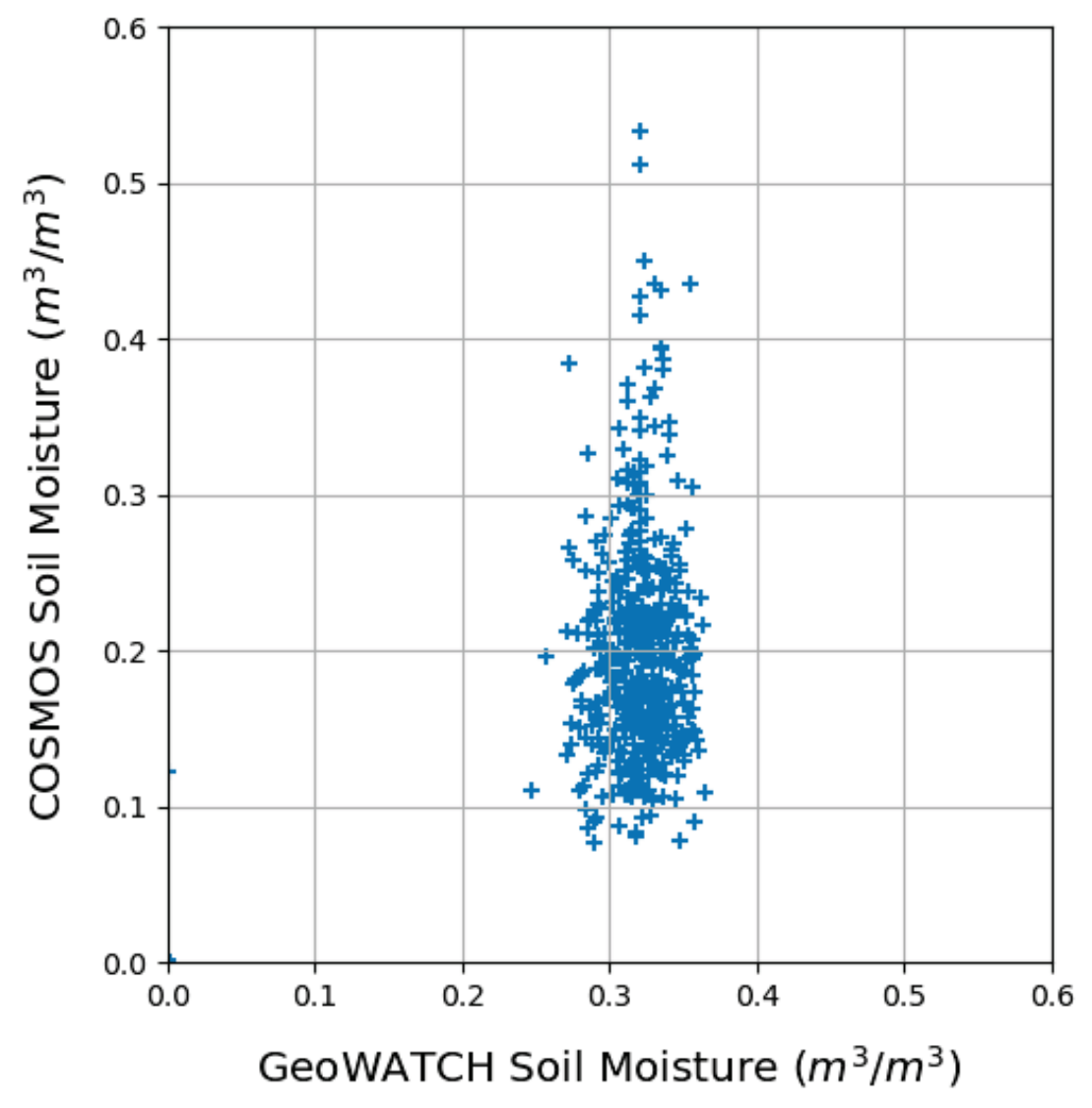

The GeoWATCH data were further compared with in situ soil moisture probes placed as part of the SMAPVEX16 study. The measurements were available beginning May 2016 and continuing on for several months.

Figure 4 includes a depiction of the locations of the probes included in the analysis, labeled as black dots with each site identification (ID). There were 17 sites within the boundaries of the GeoWATCH data pulled for this comparison study, but only two sites were within the footprint of the COSMOS measurements. Therefore, the ability to compare the GeoWATCH and COSMOS data with a quality, independent dataset is extremely limited. 
Figure 12. Histogram of GeoWATCH data for COSMOS locations (left) and the entire 00 UTC 30-May-2016 GeoWATCH dataset (right).

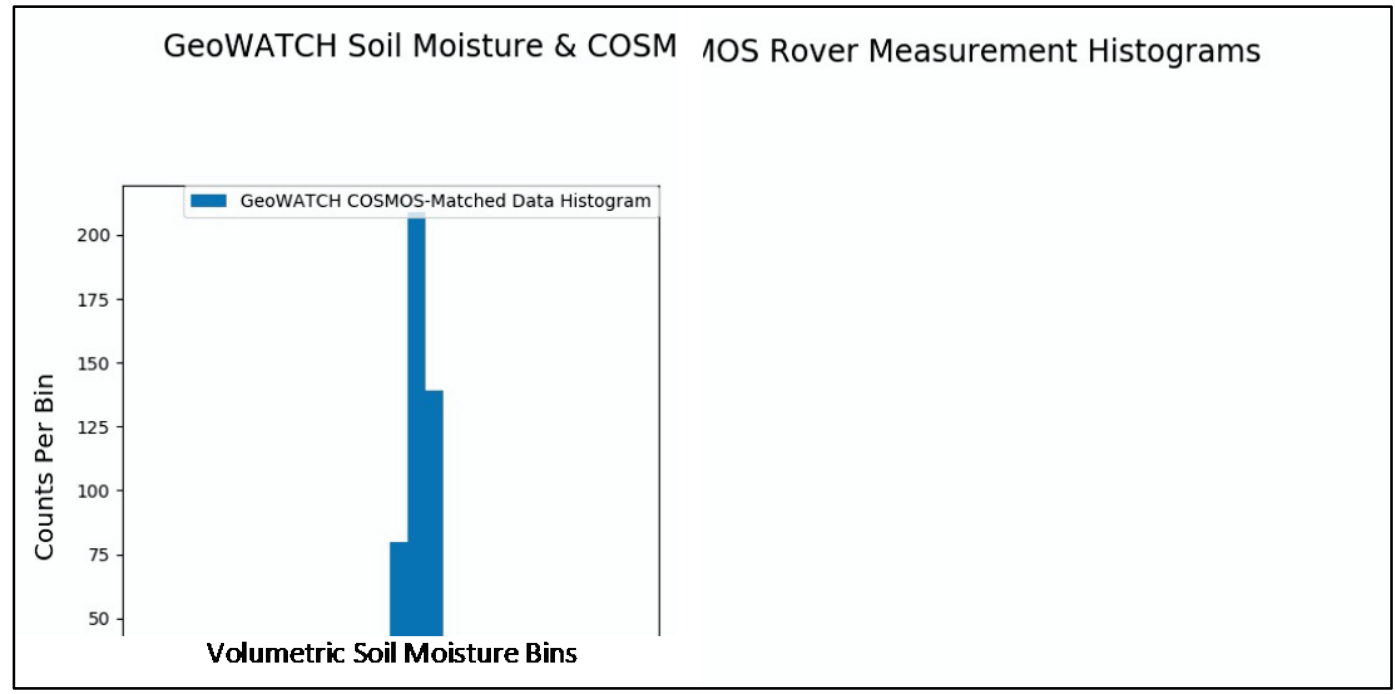

Figures 13 includes two graphs of the two in situ probes soil moisture content for SMAPVEX16 site ID 733 and 743 with the corresponding COSMOS and GeoWATCH-matched soil moisture estimates. The soil moisture probes were located at a depth of $5 \mathrm{~cm}$ below the surface. Both graphs represent volumetric soil moisture versus time for all three datasets.

The plotted data indicates a much better agreement between the GeoWATCH estimates and in situ measurements as compared to the COSMOS estimate. The COSMOS soil moisture estimate is much lower than the in situ probe, and at least one COSMOS soil moisture estimate is half that the value report by the in situ probe. The soil moisture probes in the plots provide half-hourly soil moisture observations, with the GeoWATCH observations at the appropriate time intervals on the plot and the corresponding COSMOS estimates when the vehicle passed within the $300 \mathrm{~m}$ range of the in situ probe.

The GeoWATCH data for the four cycles were compared against in situ probes for the 17 sites and represented in the graph in Figure 14. Overall, the GeoWATCH compares well to the in-situ probes, with a corresponding root mean square error of 0.05. Two of the sites were contained somewhat larger differences, site 733 and 743. Both sites were similarly situated adjacent to a drainage route separating a farm and a highway and the terrain data for GeoWATCH would then aggregate water along that lower elevation pathway. GeoWATCH does not include any water routing in streams. 
Figure 13. Plots of in situ soil moisture observations for SMAPVEX16 sites 733 (left) and 743 (right) with soil moisture estimates from the weighted average GeoWATCHmatched estimates (red circles) and the COSMOS values (green triangles).

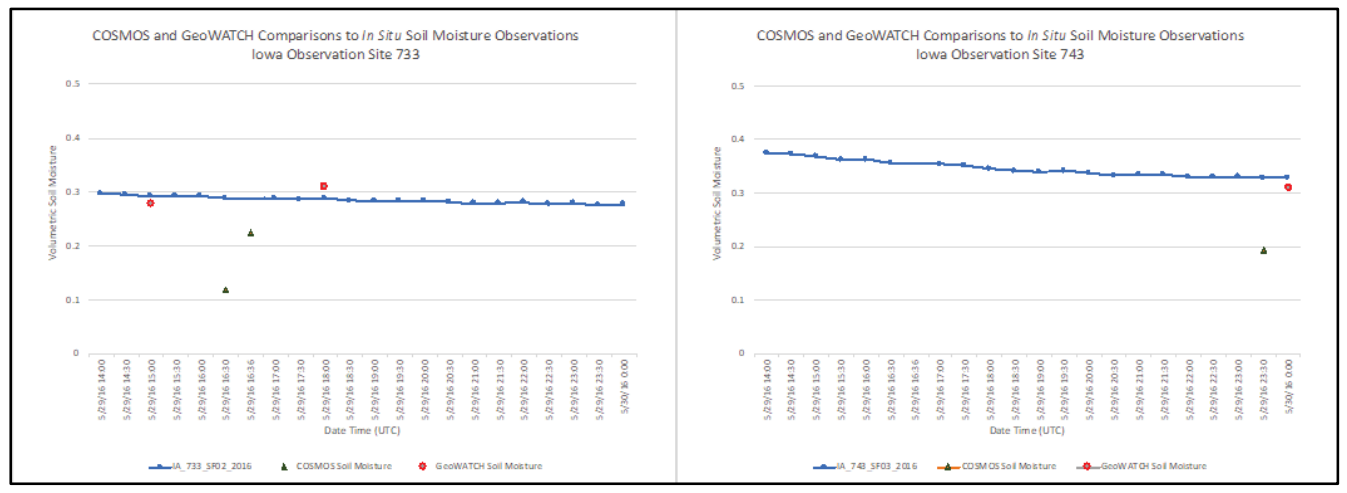

Figure 14. Plot of the in situ soil moisture probes for the 17 different SMAPVEX16 sites compare to the GeoWATCH soil moisture estimates. The root mean square error is listed in the upper right of the plot. Each SMAPVEX16 site is labeled with a different symbol shape and color combination. There were four time periods evaluated, matching the observation time of the GeoWATCH data $(15,18,21$, and 00 UTC).

GeoWATCH Soil Moisture Analysis vs. In Situ Gauges

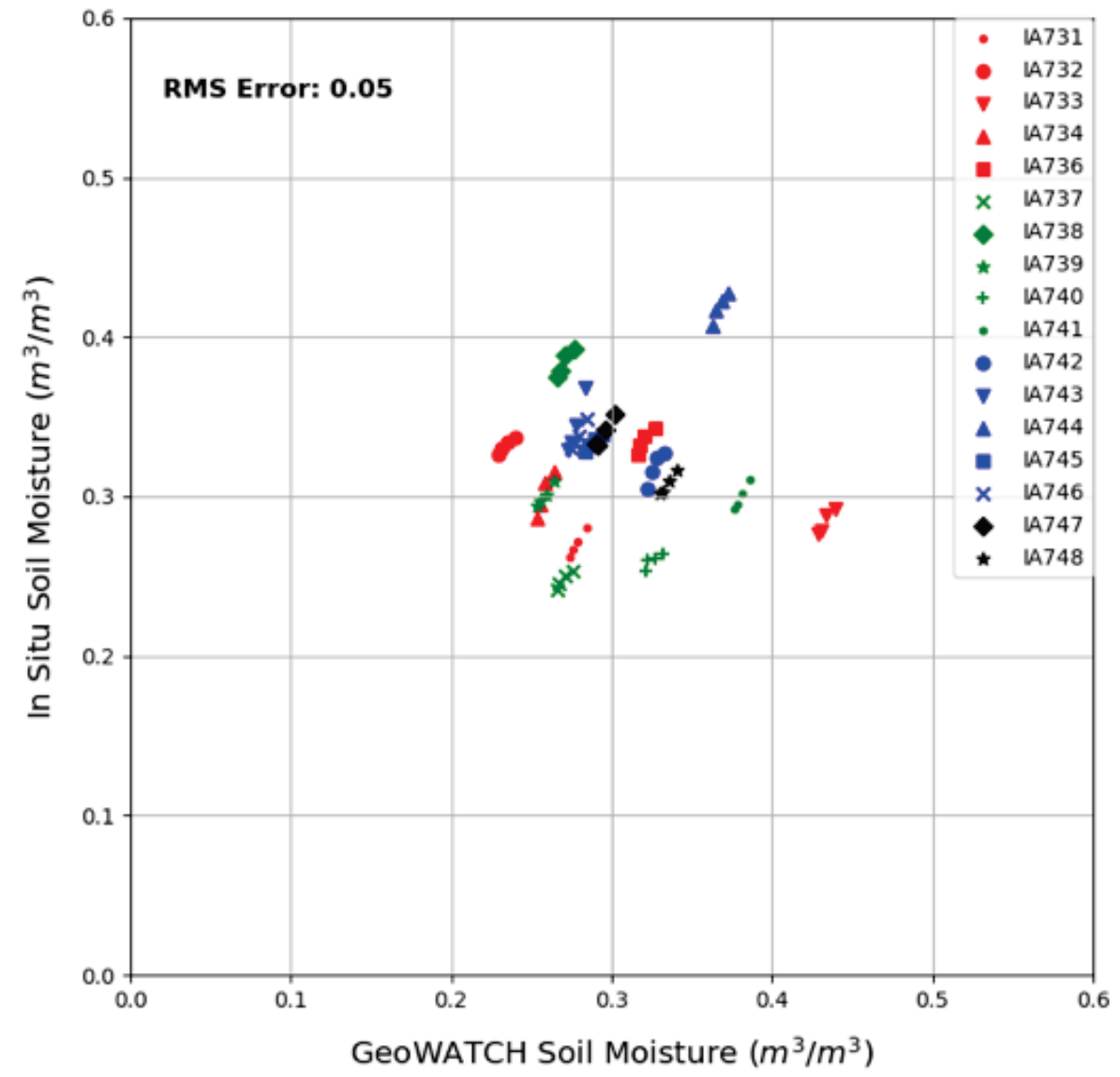


The COSMOS rover operations include two periods where the vehicle was stationary for a approximately a $15 \mathrm{~min}$ period of time at the beginning and end of the day (Figure 15). The soil moisture observations from both stationary periods were evaluated, and an average value was computed and plotted on the same graph as the GeoWATCH matched estimates. The initial stationary observation average, $0.32 \mathrm{~m} 3 / \mathrm{m}^{3}$ is nearly identical to the GeoWATCH area average estimates of $0.31 \mathrm{~m} 3 / \mathrm{m}^{3}$. The COSMOS estimate from the final $15 \mathrm{~min}$ is $0.20 \mathrm{~m}^{3} / \mathrm{m}^{3}$ while the GeoWATCH area average estimate is $0.32 \mathrm{~m}^{3} / \mathrm{m}^{3}$.

Figure 15. Comparison of the first $15 \mathrm{~min}$ (left) and last $15 \mathrm{~min}$ (right) of COSMOS rover observations (green line) with GeoWATCH area weighted soil moisture estimates (red dashed line). During the first and last $15 \mathrm{~min}$ of rover operations, the vehicle was stationary, so the observations represent a single location. The average value of the COSMOS rover estimates is the brown line.

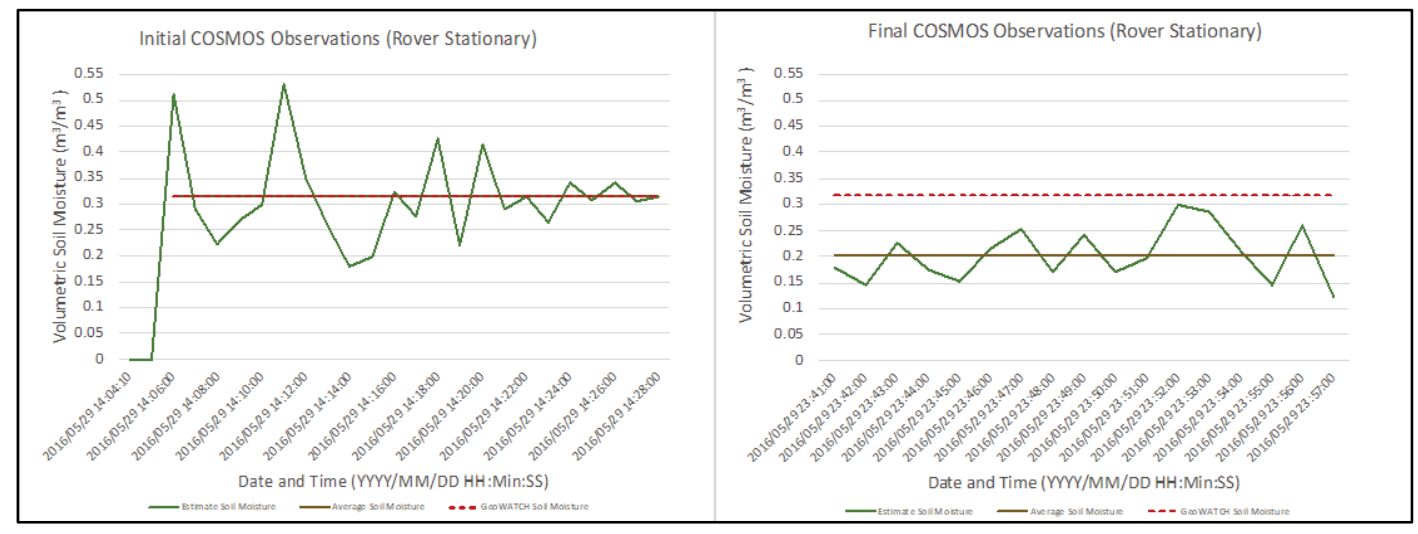




\section{Conclusion and Recommendations}

\subsection{Conclusion}

This purpose of this study was to evaluate the ERDC COSMOS rover as a potential tool to update and improve model-based predictions of soil moisture as a way to improve the computation of soil strength and mobility predictions for both manned and autonomous vehicle mobility. The first steps of the process of blending the COSMOS observations with GeoWATCH soil moisture predictions were to compare the two datasets and determine if they are correlated in space and time and to compare each set of estimates to in situ observations to evaluate accuracy.

Given that the GeoWATCH soil moisture estimates are land surface model based and lack in situ observations driving the computation, initial concerns were that the two datasets would not necessarily be correlated because the COSMOS observations would contain more information about local effects not necessarily accounted for by the model. However, after evaluating the data and comparing with in situ observations, the confidence in the GeoWATCH data is much higher. The COSMOS soil moisture observations overall were significantly lower than GeoWATCH model-produced estimates, but overall, the GeoWATCH data compared much better to in situ observations compared to the COSMOS results. The range of the COSMOS soil moisture results was much broader than the GeoWATCH data.

\subsection{Recommendations for future research}

Further study is needed. Regarding data points where COSMOS moisture observations are higher than GeoWATCH estimates, a determination should be made whether COSMOS is measuring something that GeoWATCH cannot estimate. That is to say, is there some environmental reason for COSMOS that could lead to a more accurate soil moisture assessment? This requires more study. Further, many more COSMOS rover datasets should be evaluated in comparison with in situ observations to better evaluate the sensor observations and improve the soil moisture algorithm. Additionally, if the GeoWATCH data are used to bias-correct the COSMOS observation, is the signal gained by any assimilation of COSMOS observation providing value? Are the higher soil moisture 
observations from COSMOS due to something in the real environment that GeoWATCH does not effectively analyze?

Overall, the study was beneficial to provide a set of next steps should there continue to be an evaluation of the COSMOS observations for possible assimilation into GeoWATCH. There are many unanswered questions about the estimates, but this initial comparison provides a path forward to answering some of those questions and potentially developing a way to improve GeoWATCH soil moisture and resulting soil strength and mobility predictions. 


\section{References}

Ahlvin, R. B., and P. W. Haley. 1992. NATO Reference Mobility Model, Edition II, NRMM User's Guide. Technical Report GL-91-19. Vicksburg, MS: US Army Waterways Experiment Station.

Andreasen, M., K. H. Jensen, D. Desilets, M. Zreda, H. R. Bogena, and M. C. Looms. 2017. "Cosmic-Ray Neutron Transport at a Forest Field Site: The Sensitivity to Various Environmental Conditions with Focus on Biomass and Canopy Interception." Hydrol. Earth Syst. Sci. doi:10.5194/hess-21-1875-2017.

ASTM International. 2006. "ASTM D2487-17 Standard Practice for Classification of Soils for Engineering Purposes (Unified Soil Classification System).” ASTM Stand. Guid.

Baatz, R., H. R. Bogena, H. J. Hendricks Franssen, J. A. Huisman, C. Montzka, and H. Vereecken. 2015. "An Empirical Vegetation Correction for Soil Water Content Quantification Using Cosmic Ray Probes.” Water Resour. Res. doi:10.1002/2014WRo16443.

Baylot Jr., E. A., B. Q. Gates, J. G. Green, P. W. Richmond, N. C. Goerger, G. L. Mason, C. L. Cummins, and L. S. Bunch. 2005. Standard for Ground Vehicle Mobility. ERDC TR-19-26. Vicksburg, MS: US Army Engineer Research and Development Center. https://hdl.handle.net/11681/35093.

Bieszczad, J., M. P. Ueckermann, C. A. Brooks, R. Chambers, W. E. Audette, and J. D. Walthour. 2016. "DASSP: A System for High-Resolution, Global Prediction of Soil Moisture Content and Soil Strength.” 3oth Conference on Hydrology. New Orleans Ernest N. Morial Convention Center, American Meteorological Society. https://ams.confex.com/ams/96Annual/webprogram/Paper288342.html.

Chan, S. K., R. Bindlish, P. O'Neill, T. Jackson, E. Njoku, S. Dunbar, J. Chaubell, et al. 2018. "Development and Assessment of the SMAP Enhanced Passive Soil Moisture Product.” Remote Sens. Environ. 204. doi:10.1016/j.rse.2017.08.025.

Cifelli, R., N. Doesken, P. Kennedy, L. D. Carey, S. A. Rutledge, C. Gim-mestad and T. Depue. 2005. "The Community Collaborative Rain, Hail, and Snow Network: Informal Education for Scientists and Citizens.” Bull. Amer. Meteor. Soc. 86(8)(Aug): 1069-1077.

Desilets, D., M. Zreda, and T. Prabu. 2006. "Extended Scaling Factors for in situ Cosmogenic Nuclides: New Measurements at Low Latitude.” Earth Planet. Sci. Lett. doi:10.1016/j.epsl.2006.03.051.

Dong, J., T. E. Ochsner, M. Zreda, M. H. Cosh, and C. B. Zou. 2014. "Calibration and Validation of the COSMOS Rover for Surface Soil Moisture Measurement." Vadose Zo. J. doi:10.2136/vzj2013.08.0148.

Frankenstein, S., and G. G. Koenig. 2004. Fast All Season Soil Strength (FASST). ERDC/CRREL SR-04-1. Vicksburg, MS: US Army Engineer Research and Development Center. 
Franz, T. E., A. Wahbi, and W. Avery. 2018. "Estimation of Biomass Water Equivalent via the Cosmic Ray Neutron Sensor.” Cosmic Ray Neutron Sensing: Estimation of Agricultural Crop Biomass Water Equivalent. https://link.springer.com/chapter/10.1007/978-3-319-69539-6 4

Franz, T. E., T. Wang, W. Avery, C. Finkenbiner, and L. Brocca. 2015. "Combined Analysis of Soil Moisture Measurements from Roving and Fixed Cosmic Ray Neutron Probes for Multiscale Real-Time Monitoring." Geophys. Res. Lett. doi:10.1002/2015GL063963.

Garcia-Gaines, R. A., and S. Frankenstein. 2015. USCS and the USDA Soil Classification System, Development of a Mapping Scheme. ERDC/CRREL TR-15-4. Vicksburg, MS: US Army Engineer Research and Development Center.

Grismer, M. E., K. M. Bali, and F. E. Robinson. 1995. "Field-Scale Neutron Probe Calibration and Variance Analysis for Clay Soil.” J. Irrig. Drain. Eng. doi:10.1061/(asce)0733-9437(1995)121:5(354).

Homer, Collin, Jon Dewitz, Suming Jin, George Xian, Catherine Costello, Patrick Danielson, Leila Gass, et al. 2020. "Conterminous United States land cover change patterns 2001-2016 from the 2016 National Land Cover Database." ISPRS J. Photogramm. Remote Sens. doi:10.1016/j.isprsjprs.2020.02.019.

Jin, Suming, Collin Homer, Limin Yang, Patrick Danielson, Jon Dewitz, Congcong Li, Zhe Zhu, George Xian, and Danny Howard. 2019. "Overall Methodology Design for the United States National Land Cover Database 2016 Products.” Remote Sens. doi:10.3390/rs11242971.

Köhli, M., M. Schrön, M. Zreda, U. Schmidt, P. Dietrich, and S. Zacharias . 2015. "Footprint Characteristics Revised for Field-Scale Soil Moisture Monitoring with Cosmic-Ray Neutrons.” Water Resour. Res. 51: 5772- 5790. doi:10.1002/2015WR017169.

Kumar, S. V., C. D. Peters-Lidard, J. L. Eastman, and W. K. Tao. 2008a. “An Integrated High-Resolution Hydrometeorological Modeling Testbed Using LIS and WRF." Environ. Model. Softw. doi:10.1016/j.envsoft.2007.05.012.

Kumar, S. V., R. H. Reichle, C. D. Peters-Lidard, R. D. Koster, X. Zhan, W. T. Crow, J. B. Eylander, and P. R. Houser. 2008b. "A Land Surface Data Assimilation Framework Using the Land Information System: Description and Applications.” Adv. Water Resour. doi:10.1016/j.advwatres.2008.01.013.

Kumar Sujay V., Christa D. Peters-Lidard, David Mocko, Rolf Reichle, Yuqiong Liu, Kristi R. Arsenault, Youlong Xia, Michael Ek, George Riggs, Ben Livneh, and Michael Cosh. 2014. "Assimilation of Remotely Sensed Soil Moisture and Snow Depth Retrievals for Drought Estimation.” J. Hydrometeorol. doi:10.1175/JHM-D-130132.1.

Lacerda, M. P. C., J. A. M. Demattê, M. V. Sato, C. T. Fongaro, B. C. Gallo, and A. B. Souza. 2016. "Tropical Texture Determination by Proximal Sensing Using a Regional Spectral Library and its Relationship with Soil Classification.” Remote Sens. doi:10.3390/rs8090701.

Mason, G., R. Ahlvin, and J. Green. 2001. Short-Term Operational Forecasts of Trafficability. ERDC/GSL TR-01-22. Vicksburg, MS: US Army Engineer Research and Development Center.. 
Merlin, O., J. P. Walker, A. Chehbouni, and Y. Kerr. 2008. “Towards Deterministic Downscaling of SMOS Soil Moisture Using MODIS Derived Soil Evaporative Efficiency." Remote Sens. Environ. doi:10.1016/j.rse.2008.06.012.

Meyer, Marvin P., I. Robert Ehrlich, David Sloss, Newell K. Murphy, Jr., Robert D. Wismer, and Tibor Czako. 1977. "International Society for Terrain-Vehicle Systems Standards.” Journal of Terramechanics 14(3): 153-182.

Monerris, A., and T. Schmugge. 2009. "Soil Moisture Estimation Using L-Band Radiometry." Advances in Geoscience and Remote Sensing. doi: 10.5772/8334.

Munoz-Carpena, R. 2004. "Field Devices for Monitoring Soil Water Content." Bull. Inst. Food Agric. Sci. Univ. Florida. https://edis.ifas.ufl.edu/ae266

Ochsner, Tyson E., Michael H. Cosh, Richard H. Cuenca, Wouter A. Dorigo, Clara S. Draper, Yutaka Hagimoto, Yann H. Kerr, Kristine M. Larson, Eni G. Njoku, Eric E. Small, and Marek Zreda. 2013. "State of the Art in Large-Scale Soil Moisture Monitoring.” Soil Sci. Soc. Am. J. doi:10.2136/sssaj2013.03.0093.

Panciera, R., J. P. Walker, and O. Merlin. 2009. "Improved Understanding of Soil Surface Roughness Parameterization for L-Band Passive Microwave Soil Moisture Retrieval.” IEEE Geosci. Remote Sens. Lett. doi:10.1109/LGRS.2009.2013369.

Peters-Lidard, C. D., P. R. Houser, Y. Tian, S. V. Kumar, J. Geiger, S. Olden, L. Lighty, et al. 2007. "High-Performance Earth System Modeling with NASA/GSFC's Land Information System.” Innov. Syst. Softw. Eng. doi:10.1007/s11334-007-0028-x.

Priddy, J. D., B. Gates, R. Mcgruder, M. Puhr, G. B. Mckinley, and B. Webb. 2019. "Ground Vehicle Performance Assessments Using the Mobility Analysis Tool." The ISTVS 15th European-African Regional Conference, Prague, Czech Republic

Reichle, R. H., D. B. McLaughlin, and D. Entekhabi. 2002. "Hydrologic Data Assimilation with the Ensemble Kalman Filter." Mon. Weather Rev. doi:10.1175/15200493(2002)130<0103:hdawte>2.0.c0;2.

Rosolem, R., W. J. Shuttleworth, M. Zreda, T. E. Franz, X. Zeng, and S. A. Kurc. 2013. "The Effect of Atmospheric Water Vapor on Neutron Count in the Cosmic-Ray Soil Moisture Observing System.” J. Hydrometeorol. doi:10.1175/JHM-D-120120.1.

Smith, J. E., L. S. Heath, and J. C. Jenkins. 2003. Forest Volume-to-Biomass Models and Estimates of Mass for Live and Standing Dead Trees of U. S. Forests. https://www.nrs.fs.fed.us/pubs/6611

Soil Survey Staff, Web Soil Survey. 2019. Nat. Resour. Conserv. Serv. United States Dep. Agric. Web Soil Surv. https://websoilsurvey.nrcs.usda.gov/

Stevens, M. T., B. W. Towne, G. L. Mason, J. D. Priddy, J. E. Osorio, and C. A. Barela. 2013. Procedures for One-Pass Vehicle Cone Index (VCI1) Determination for Acquisition Support. ERDC/GSL SR-13-2. Vicksburg, MS: US Army Engineer Research and Development Center. 
Stoffler, R. O. 2017. “The USAF GALWEM: Improving Military Decision Making, Advancing National Capability." 28th Conference on Weather Analysis and Forecasting / 24th Conference on Numerical Weather Prediction, Washington State Convention Center, American Meteorological Society Annual Meeting.

Sullivan, P. M., C. D. Bullock, N. A. Renfroe, M. R. Albert, G. G. Koening, L. Peck, and K. O’Neill. 1997. Soil Moisture Strength Prediction Model Version II (SMSP II). ERDC TR-o0-2. Vicksburg, MS: US Army Engineer Research and Development Center.

Ueckermann, M. P., J. Bieszczad, and D. R. Callender. 2018. "A RESTful API for PythonBased Server-Side Analysis of High-Resolution Soil Moisture Downscaling Data." Proceedings, Eighth Symposium on Advances in Modeling and Analysis Using Python, 8-11 January, Austin, TX., American Meteorological Society Annual Meeting https://ams.confex.com/ams/98Annual/webprogram/Paper332957.html.

US Army. 1959. Soils Trafficability. TB ENG 37. Washington, DC: Headquarters, Department of the Army.

US Army. 1990. Terrain Analysis. FM 5-33. Washington, DC: Department of the Army.

US Army. 2010. Geospatial Engineering. ATTP 3-34.80. Washington, DC: Headquarters, Department of the Army.

Vather, T., C. Everson, and T. E. Franz. 2019. "Calibration and Validation of the Cosmic Ray Neutron Rover for Soil Water Mapping within Two South African Land Classes." Hydrology. doi:10.3390/hydrology6030065.

WES (US Army Engineer Waterways Experiment Station). 1961. Trafficability of Soils: Soil Classification. Technical Memorandum No. 3-240 and Supplements 1 through 20. Vicksburg, MS: US Army Engineer Waterways Experiment Station.

Wu, X., J. P. Walker, C. Rüdiger, and R. Panciera. 2015. "Effect of Land-Cover Type on the SMAP Active/Passive Soil Moisture Downscaling Algorithm Performance.” IEEE Geosci. Remote Sens. Lett. 12: 846-850. doi:doi:10.1109/LGRS.2014.2364049.

Yang, Limin, Suming Jin, Patrick Danielson, Collin Homer, Leila Gass, Stacie M. Bender, Adam Case, et al. 2018. "A New Generation of the United States National Land Cover Database: Requirements, Research Priorities, Design, and Implementation Strategies.” ISPRS J. Photogramm. Remote Sens. doi:10.1016/j.isprsjprs.2018.09.006.

Zreda, M., D. Desilets, T. P. A. Ferré, and R. L. Scott. 2008. "Measuring Soil Moisture Content Non-Invasively at Intermediate Spatial Scale Using Cosmic-Ray Neutrons." Geophys. Res. Lett. doi:10.1029/2008GL035655.

Zreda, M., W. J. Shuttleworth, X. Zeng, C. Zweck, D. Desilets, T. Franz, and R. Rosolem. 2012. "COSMOS: The Cosmic-Ray Soil Moisture Observing System." Hydrol. Earth Syst. Sci. doi:10.5194/hess-16-4079-2012. 


\section{Unit Conversion Factors}

\begin{tabular}{|c|c|c|}
\hline Multiply & By & To Obtain \\
\hline acres & $4,046.873$ & square meters \\
\hline acre-feet & $1,233.5$ & cubic meters \\
\hline atmosphere (standard) & 101.325 & kilopascals \\
\hline cubic feet & 0.02831685 & cubic meters \\
\hline cubic inches & $1.6387064 \mathrm{E}-05$ & cubic meters \\
\hline cubic yards & 0.7645549 & cubic meters \\
\hline degrees (angle) & 0.01745329 & radians \\
\hline degrees Fahrenheit & $(F-32) / 1.8$ & degrees Celsius \\
\hline feet & 0.3048 & meters \\
\hline gallons (US liquid) & 3.785412 E-03 & cubic meters \\
\hline hectares & $1.0 \mathrm{E}+04$ & square meters \\
\hline inches & 0.0254 & meters \\
\hline inch-pounds (force) & 0.1129848 & newton meters \\
\hline knots & 0.5144444 & meters per second \\
\hline miles (nautical) & 1,852 & meters \\
\hline miles (US statute) & $1,609.347$ & meters \\
\hline miles per hour & 0.44704 & meters per second \\
\hline square feet & 0.09290304 & square meters \\
\hline square inches & $6.4516 \mathrm{E}-04$ & square meters \\
\hline square miles & $2.589998 E+06$ & square meters \\
\hline yards & 0.9144 & meters \\
\hline
\end{tabular}




\section{Acronyms and Abbreviations}

$\begin{array}{ll}\text { 557WW } & \text { 557th Weather Wing } \\ \text { CCM } & \text { Cross-country mobility } \\ \text { CI } & \text { cone index } \\ \text { COSMOS } & \text { Cosmic-ray Soil Moisture Observing System } \\ \text { CSV } & \text { comma separated values } \\ \text { ERDC } & \text { US Army Engineer Research and Development Center } \\ \text { GALWEM } & \text { Global Air Land Weather Exploitation Model } \\ \text { Geo-WATCH } & \text { Geospatial Weather-Affected Terrain Conditions and Hazards } \\ \text { ID } & \text { identification } \\ \text { LIS } & \text { Land Information System } \\ \text { NASA } & \text { National Aeronautics and Space Administration } \\ \text { NLCD } & \text { National Land Cover Database } \\ \text { NRMM } & \text { NATO Reference Mobility Model } \\ \text { RCI } & \text { rating cone index } \\ \text { RI } & \text { remold index } \\ \text { StndMob } & \text { Standard Mobility Application } \\ \text { SDB } & \text { standing dry biomass } \\ \text { SMAP } & \text { Soil Moisture Active/Passive } \\ \text { SMAPVEX16 } & \text { Soil Moisture Active/Passive (SMAP) Validation Experiment 2016 } \\ \text { SMOS } & \text { Soil Moisture and Ocean Salinity } \\ \text { SWB } & \text { standing wet biomass } \\ & \\ \text { NW } & \end{array}$




$\begin{array}{ll}\text { USACE } & \text { US Army Corps of Engineers } \\ \text { USCS } & \text { Unified Soil Classification System } \\ \text { USDA } & \text { US Department of Agriculture } \\ \text { VCI } & \text { vehicle cone index } \\ \text { WCS } & \text { web coverage services } \\ \text { WES } & \text { Waterways Experiment Station }\end{array}$




\section{Glossary}

The following are definitions of specialized terms used in this report.

1. Cone Index (CI). An index of soil shear strength obtained using a trafficability cone penetrometer standardized at the US Army Engineer Waterways Experiment (WES).

2. Critical Layer. A layer of soil lying below the natural terrain surface that exerts the greatest influence on trafficability.

3. Mobility. The overall capability of a vehicle to move from place to place while retaining its ability to perform its primary mission (Meyer et al. 1977).

4. Moisture Content (gravimetric). Ratio of the weight of water over the weight of solid particles in a mass of soil, normally expressed as a percentage.

5. Rating Cone Index (RCI). An index of soil shear-strength that includes consideration of the sensitivity of soil to strength losses under vehicular traffic. It is defined as the product of Cone Index (CI) and Remold Index (RI) for the particular layer of soil.

6. Remold Index (RI). An index of the sensitivity of soil to strength losses under vehicular traffic obtained using remolding equipment standardized at WES.

7. Sinkage. The depth to which the traction elements penetrate the terrain, measured normal to the original, undisturbed surface.

8. Trafficability. The ability of terrain to support the passage of vehicles (Meyer et al. 1977).

9. Unified Soil Classification System (USCS). A system which identifies (classifies) soils according to their textural and plasticity qualities and to their grouping with respect to their performances as engineering construction materials (Meyer et al. 1977).

10. Vehicle Cone Index (VCI). The minimum soil strength required for a vehicle to consistently make a specified number of passes. Consideration is most often given to one-pass (VCI1) and fifty-pass (VCI50) soil strengths. 


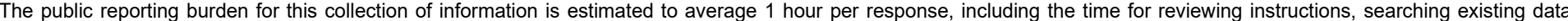

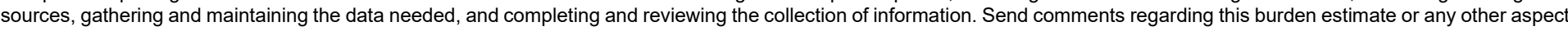

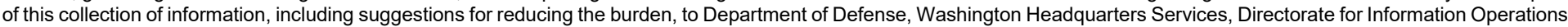

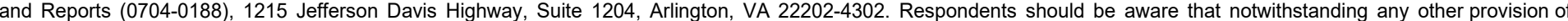
law, no person shall be subject to any penalty for failing to comply with a collection of information if it does not display a currently valid OMB control number. PLEASE DO NOT RETURN YOUR FORM TO THE ABOVE ADDRESS.

\begin{tabular}{l|l|l}
\hline 1. REPORT DATE & $\begin{array}{l}\text { 2. REPORT TYPE } \\
\text { Final Report }\end{array}$ & 3. DATES COVERED (From - To) \\
September 2021 & \begin{tabular}{l} 
Final \\
\hline
\end{tabular}
\end{tabular}

\section{TITLE AND SUBTITLE}

An Investigation of the Feasibility of Assimilating COSMOS Soil Moisture into GeoWATCH

5a. CONTRACT NUMBER

5b. GRANT NUMBER

5c. PROGRAM ELEMENT NUMBER

0633462A

6. AUTHOR(S)

John B. Eylander, Michael G. Lewis, Maria T. Stevens, John G. Green, Stephanie J. Price, and Joshua R. Fairley

5d. PROJECT NUMBER

480361

5e. TASK NUMBER

SBG302

5f. WORK UNIT NUMBER

\section{PERFORMING ORGANIZATION NAME(S) AND ADDRESS(ES) (see reverse)}

\section{PERFORMING ORGANIZATION REPORT NUMBER}

ERDC TR-21-15

10. SPONSOR/MONITOR'S ACRONYM(S) N/A

Deputy Assistant Secretary of the Army (Research and Technology)

102 Army Pentagon

Washington, DC 20314-1000

\section{SPONSOR/MONITOR'S} REPORT NUMBER(S)

\section{DISTRIBUTION/AVAILABILITY STATEMENT}

Approved for public release; distribution is unlimited.

\section{SUPPLEMENTARY NOTES}

\section{ABSTRACT}

This project objective evaluated the potential of improving linked weather-and-mobility model predictions by blending soil moisture observations from a Cosmic-ray Soil Moisture Observing System (COSMOS) sensor with weather-informed predictions of soil moisture and soil strength from the Geospatial Weather-Affected Terrain Conditions and Hazards (GeoWATCH). Assimilating vehicle-borne COSMOS observations that measure local effects model predictions of soil moisture offered potential to produce more accurate soil strength and vehicle mobility forecast was the hypothesis. This project compared soil moisture observations from a COSMOS mobile sensor driven around an area near Iowa Falls, IA, with both GeoWATCH soil moisture predictions and in situ probe observations. The evaluation of the COSMOS rover data finds that the soil moisture measurements contain a low measurement bias while the GeoWATCH estimates more closely matched the in situ data. The COSMOS rover captured a larger dynamic range of soil moisture conditions as compared to GeoWATCH, capturing both very wet and very dry soil conditions, which may better flag areas of high risk for mobility considerations. Overall, more study of the COSMOS rover is needed to better understand sensor performance in a variety of soil conditions to determine the feasibility of assimilating the COSMOS rover estimates into GeoWATCH.

\section{SUBJECT TERMS}

Shear strength of soils_-Testing, Soil mechanics, Soil moisture-Measurements, Trafficability, Weather forecasting--Models

\section{SECURITY CLASSIFICATION OF:}

\begin{tabular}{|l|l|l|}
\hline a. REPORT & b. ABSTRACT & c. THIS PAGE \\
Unclassified & Unclassified & Unclassified \\
\hline
\end{tabular}

17. LIMITATION OF ABSTRACT

SAR
18. NUMBER OF PAGES

53 19a. NAME OF RESPONSIBLE PERSON John B. Eylander

19b. TELEPHONE NUMBER (Include area code) 603-646-4188 


\section{PERFORMING ORGANIZATION NAME(S) AND ADDRESS(ES) (continued)}

Coastal and Hydraulics Laboratory

US Army Engineer Research and Development Center 3909 Halls Ferry Rd

Vicksburg, MS 39180-6199

Geospatial Research Laboratory

US Army Engineer Research and Development Center 7701 Telegraph Rd

Alexandria, VA 22315-3822

Geotechnical and Structures Laboratory

US Army Engineer Research and Development Center 3909 Halls Ferry Rd

Vicksburg, MS 39180-6199 